\title{
Effects of Friction Stir Processing on the Microstructure and Mechanical Properties of Fusion Welded 304L Stainless Steel
}

Colin J. Sterling

Brigham Young University - Provo

Follow this and additional works at: https://scholarsarchive.byu.edu/etd

Part of the Mechanical Engineering Commons

\section{BYU ScholarsArchive Citation}

Sterling, Colin J., "Effects of Friction Stir Processing on the Microstructure and Mechanical Properties of Fusion Welded 304L Stainless Steel" (2004). Theses and Dissertations. 46.

https://scholarsarchive.byu.edu/etd/46

This Thesis is brought to you for free and open access by BYU ScholarsArchive. It has been accepted for inclusion in Theses and Dissertations by an authorized administrator of BYU ScholarsArchive. For more information, please contact scholarsarchive@byu.edu, ellen_amatangelo@byu.edu. 
EFFECTS OF FRICTION STIR PROCESSING ON THE MICROSTRUCTURE AND MECHANICAL PROPERTIES OF FUSION WELDED 304L STAINLESS STEEL

by

Colin J. Sterling

\begin{abstract}
A thesis submitted to the faculty of
Brigham Young University

in partial fulfillment of the requirements for the degree of
\end{abstract}

Master of Science

Department of Mechanical Engineering

Brigham Young University

August 2004 
Copyright (C) 2004 Colin J. Sterling

All Rights Reserved 


\section{BRIGHAM YOUNG UNIVERSITY GRADUATE COMMITTEE APPROVAL}

of a thesis submitted by

Colin J. Sterling

This thesis has been read by each member of the following graduate committee and by majority vote has been found to be satisfactory.

Date

Date

Date
Tracy W. Nelson, Chair

Carl D. Sorensen

Kenneth W. Chase 


\section{BRIGHAM YOUNG UNIVERSTIY}

As chair of the candidate's graduate committee, I have read the thesis of Colin J. Sterling in its final form and have found that 1) its format, citations, and bibliographical style are consistent and acceptable and fulfill university and department style requirements; 2) its illustrative materials including figures, tables, and charts are in place; and 3) the final manuscript is satisfactory to the graduate committee and is ready for submission to the university library.

Date

Accepted for the Department
Tracy W. Nelson

Chair, Graduate Committee
Brent L. Adams

Department Chair

Accepted for the College

Douglas M. Chabries

Dean, College of Engineering and Technology 


\begin{abstract}
EFFECTS OF FRICTION STIR PROCESSING ON THE MICROSTRUCTURE AND MECHANICAL PROPERTIES OF FUSION WELDED 304L STAINLESS STEEL
\end{abstract}

\author{
Colin J. Sterling \\ Department of Mechanical Engineering \\ Master of Science
}

Friction stir processing (FSP) has been utilized to locally process regions of arc weldments in 304L stainless steel to improve the microstructure and mechanical performance. The cast microstructure and coarse delta-ferrite has been replaced with a fine-grained wrought microstructure. Furthermore, twins were introduced throughout the friction stir processed region. The introduction of sub-surface sigma and carbide during FSP is not expected to adversely affect the resulting mechanical or corrosion properties of friction stir processed $304 \mathrm{~L}$ arc welds. It is expected that the improved microstructure will lead to improved stress corrosion cracking and general corrosion properties. The resulting mechanical properties of FS processed weldments were also an improvement over as-welded arc welds. FSP resulted in an increase of $6 \%$ for both yield and ultimate strength. 


\section{ACKNOWLEDGEMENTS}

I would like to thank my fellow students and researchers who have worked at the FSRL for their help and support. I would also like to thank all those who believe in FSW and have made this research possible. Finally, I would like to thank Christin who has been my source of support and strength throughout this process. 


\section{Table of Contents}

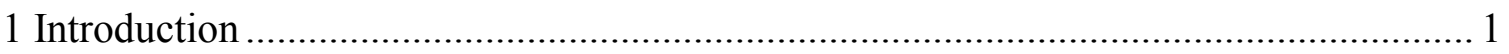

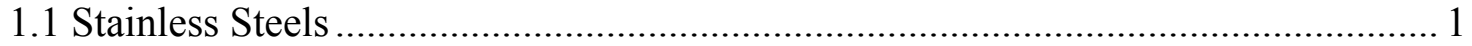

1.1.1 Austenitic Stainless Steels........................................................................ 1

1.1.2 Welding Austenitic Stainless Steels ............................................................... 2

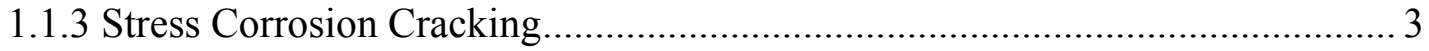

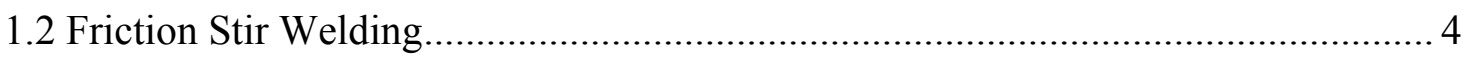

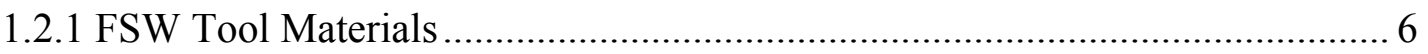

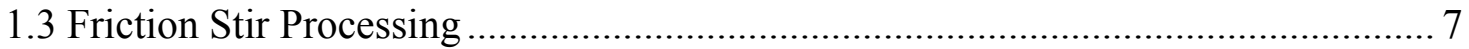

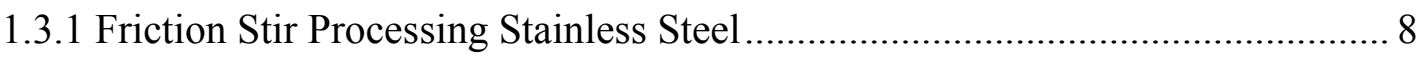

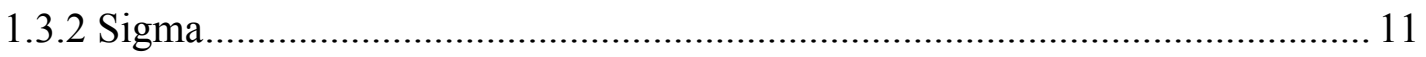

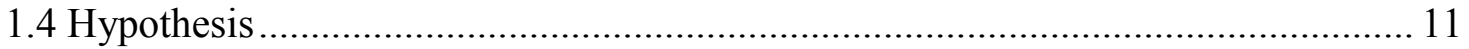

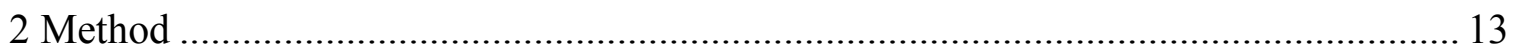



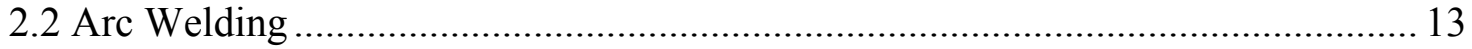

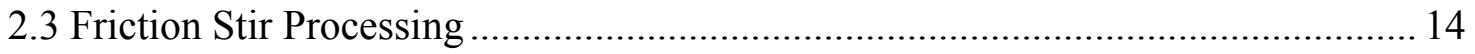

2.4 FS Processed Arc Weld Evaluation ........................................................... 15

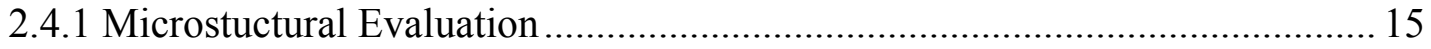

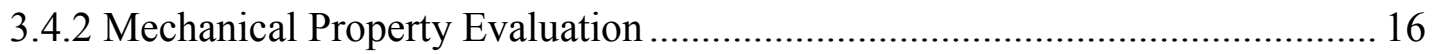

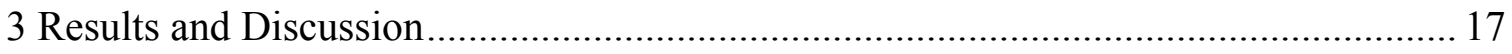

3.1 Macrostructural Comparison of FS Processed Arc Welds vs. FS Processed

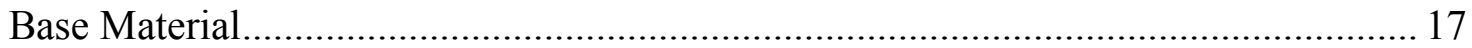

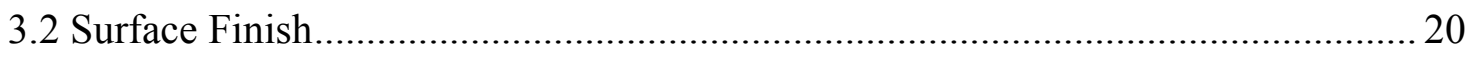

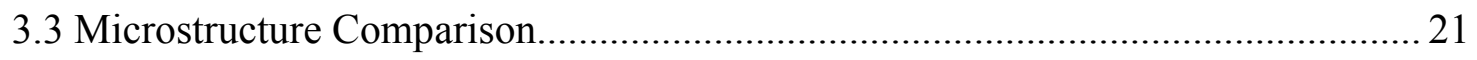

3.3.1 Austenitic Region Microstructure …...................................................... 21

3.3.2 Multi-phase Region Microstructure .......................................................... 22

3.3.3 General Stir Zone Microstructure Improvements ...................................... 23 


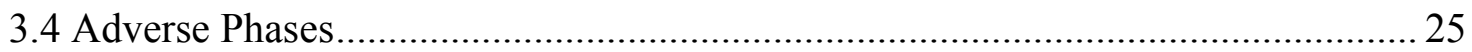

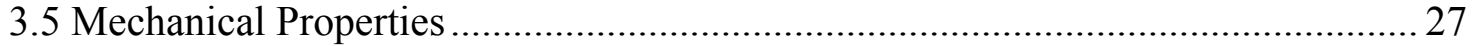

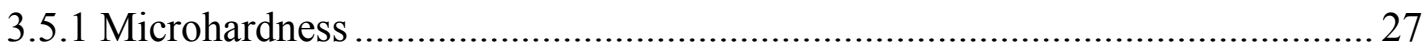

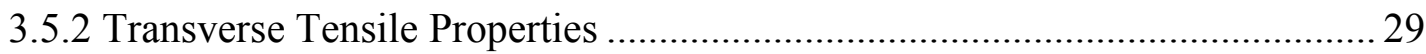

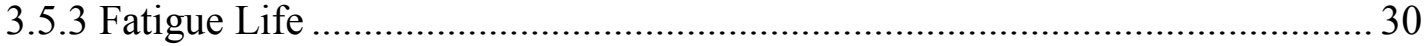

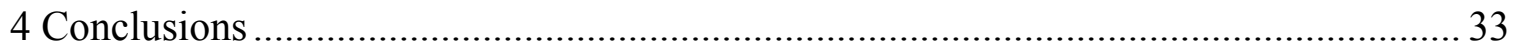

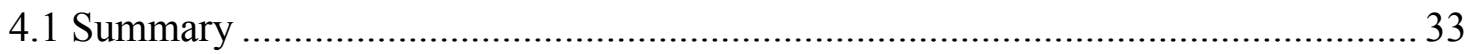



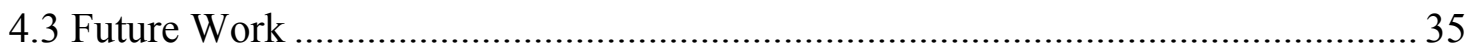

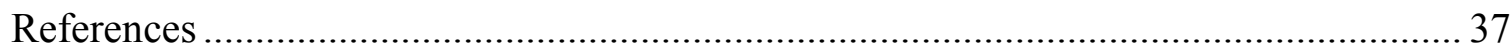




\section{List of Figures}

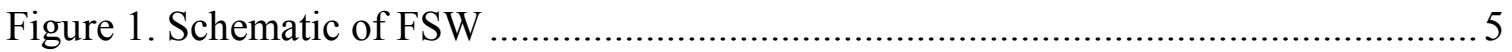

Figure 2. Cross section of FSP in 316L autogenous weld ........................................ 8

Figure 3. Photomicrographs of a) arc welded 316L and b) FS processed zone................. 9

Figure 4. Typical FSP zone, shown from section processed at 800 RPM and 50 $\mathrm{mm} / \mathrm{min}$

Figure 5. Optical macrographs indicating the effect of processing parameters on resulting microstructure in 304L stainless steel a) processed at $400 \mathrm{rpm}$ and 50 $\mathrm{mm} / \mathrm{min} \mathrm{b}$ ) processed at $800 \mathrm{rpm}$ and $130 \mathrm{~mm} / \mathrm{min}$

Figure 6. Cross section of 304L arc weld produced with 308 filler material.................... 13

Figure 7. a) Tool drawing and b) illustration of liquid cooled tool holder and telemetry thermal couple systems

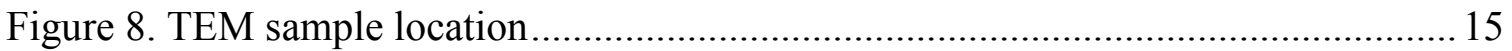

Figure 9. a) Transverse macrophotograph showing general structure of FS processed 304L arc welds b) micrograph showing sharp difference between austenite and multi-phase region c) edge of advancing side SZ lacking elongated uplifted grains

Figure 10. Photographs showing FSP surface finish in a) 304L plate and b) arc welded $304 \mathrm{~L}$ plate

Figure 11. Surface finish in FS processed 304L stainless steel welded with austenitic filler material

Figure 12. Photomicrographs of a) unaffected base metal and b) retreating side of an FS processed 304L arc weld and OIM ${ }^{\mathrm{TM}}$ results showing the grain size distribution in c) unaffected base metal and d) retreating side of an FS processed 304L arc weld3.3.2 Multi-phase Region Microstructure

Figure 13. OIM ${ }^{\mathrm{TM}}$ maps showing the phase morphology in a) the arc weld (austenite is green, ferrite is red) and b) the FS processed arc weld 
Figure 14. Photographs showing a) macro of an arc weld before FSP b) the top surface of the arc weld prior to FSP c) top of the advancing side SZ and d) top of the retreating side $\mathrm{SZ}$.

Figure 15. Phase identification images a) photomicrograph showing sigma (bright blue) b) TEM negative showing sigma at a triple point and backscatter images showing austenite (light gray), ferrite (darker gray), and archives of sigma (black) located in c) the lower FS processed region and d) the upper FS processed region

Figure 16. Photomicrographs showing a) low density of carbide (small black spots) near the surface of the FS processed arc weld and b) a higher concentration of carbide at the lower region of the SZ

Figure 17. Microhardness Map of FS processed arc weld with lines approximating the location of the fusion weld (straight lines) and stir zone (curved line)

Figure 18. Comparison of tensile properties and elongation of as-welded vs. as-FS processed

Figure 19. High cycle fatigue curve for arc welds, FS processed arc welds, and arc welds with the bead ground flush. 


\section{List of Acronyms}

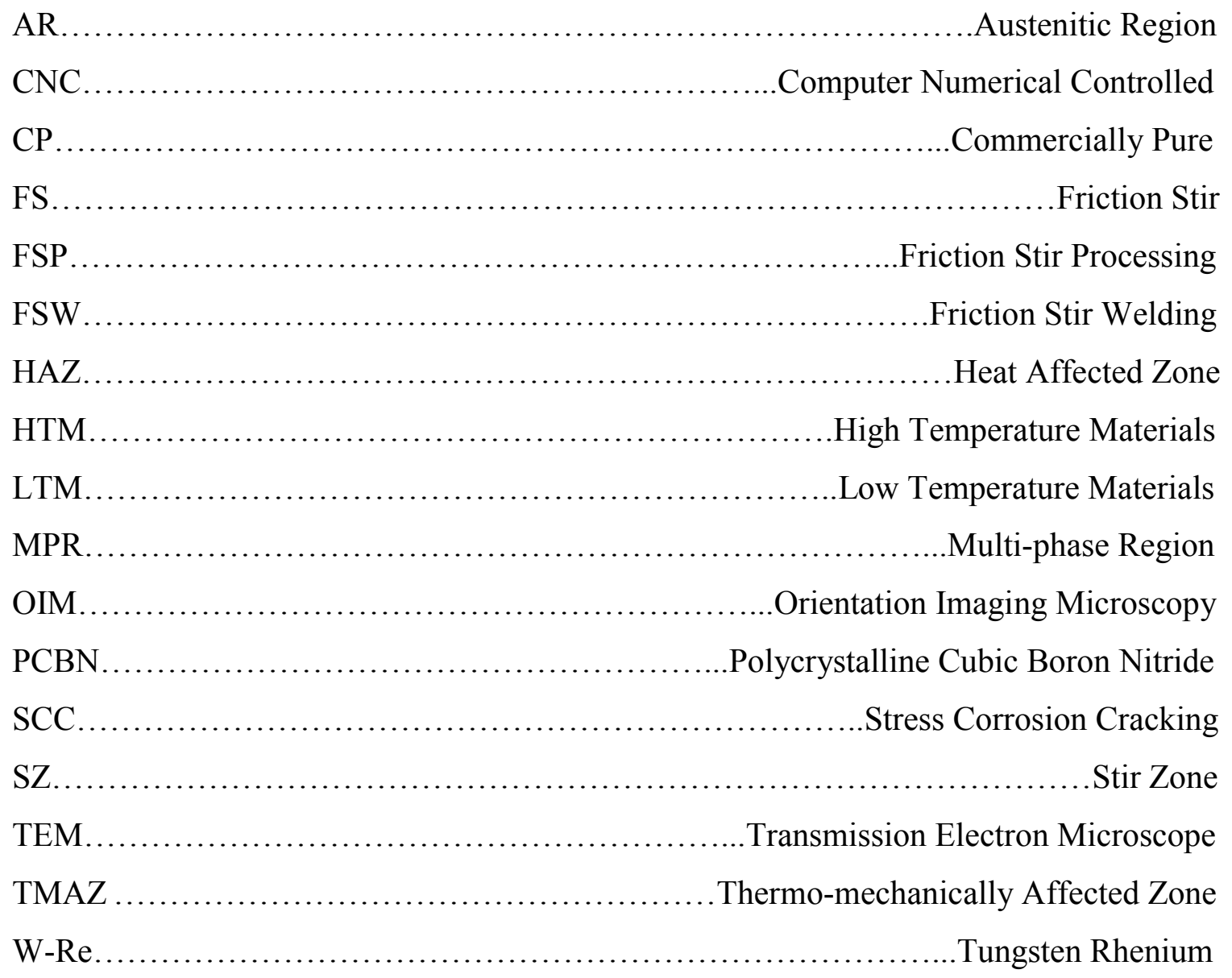




\section{Introduction}

\subsection{Stainless Steels}

Around the turn of the twentieth century it was discovered that by adding at least $12 \%$ chromium by weight steels became more corrosion resistant than common carbon steels. The addition of chrome caused the spontaneous formation of a passive protective layer, which reduced the rate of surface dissolution [Ref 1]. As the science of metallurgy progressed, it was found that by further alloying steels with elements such as nickel, molybdenum, copper, titanium, aluminum, silicone, niobium, nitrogen, sulfur, and selenium, other desirable properties could be selectively created.

While stainless steels are generally defined as an iron alloy containing a minimum of 12 wt. \% chromium, they may be further categorized into several sub-categories. These categories are martensitic, ferritic, duplex, precipitation hardenable and austenitic.

\subsubsection{Austenitic Stainless Steels}

Austenitic stainless steels are probably the most common and most used of all the stainless steels. The most common austenitic family, the 300 series, is an iron-chromenickel system. Austenitic stainless steels are considered to be very resistant to corrosion due to the high wt. \% chromium and nickel content (18-20 and 8-12 respectively). They are not magnetic, nor are they hardenable by heat treatment. However, they can be hardened significantly by cold working. Austenitic stainless steels are used extensively in petrochemical, nuclear, and corrosive chemical environments [Ref 2-4]

Austenitic stainless steels are further defined by the carbon content as; "L" grades, straight grades, and " $\mathrm{H}$ " grades. The L grades contain $\leq 0.03 \mathrm{wt}$. \% C, the straight grades 
contain $0.03-0.08$ wt. \% $\mathrm{C}$, and the $\mathrm{H}$ grades contain anywhere from $0.04-0.10$ wt. \% C. The higher carbon content of the $\mathrm{H}$ grades produces a harder and more wear resistant material. The increased carbon also helps the material hold its strength at high temperatures and is therefore often used in high temperature applications. However, the increase in carbon leads to problems in the heat affected zone (HAZ) of the welds and is discussed in the next section. The lower carbon content of the $\mathrm{L}$ grades were specifically designed for improved weldability.

\subsubsection{Welding Austenitic Stainless Steels}

Arc welding has long been considered a viable process for joining ferrous materials; austenitic stainless steels are no exception. Inherent in the arc welding process however, are certain problems, which keep it from being an "ideal" process.

Typical of all arc welding processes, problems such as chemical inhomogeneites in the weld, microporosity, cold laps, microfissures, and hot cracks reduce the quality of the joint [Ref 5]. Austenitic stainless steels are particularly prone to the hot cracking phenomenon. It has been determined however, that hot cracking may be reduced in austenitic stainless steel weldments by using filler materials that contain a small percentage of retained ferrite $[\operatorname{Ref} 1,4,6]$. Although appropriate filler materials have been developed, problems still arise especially in the root of weldments, where the filler material may be diluted by the high amount of austenite in the parent material. Furthermore, the slower cooling rate at the root with respect to the rest of the weld nugget reduces the amount of retained ferrite and increases the likelihood of hot cracking [Ref $4,6]$.

While filler materials are able to compensate for undesired changes in the microstructure of the solidified region, they cannot prevent the microstructural changes in the HAZ. When steel is held at a critical temperature range $\left(600-800^{\circ} \mathrm{C}\right)$ chrome precipitates out of the matrix and forms chrome carbides at the grain boundaries. The formation of chrome carbides produces a chemical inhomogeneity in the surrounding grains; they become 
depleted in chromium with respect to the base material. When these precipitates cause the surrounding areas to have less than about $13 \mathrm{wt}$ \% chrome, the areas become susceptible to corrosion. Keeping the carbon content low reduces this problem by reducing the amount of chromium being precipitated at the grain boundaries.

When post-weld annealing is possible, high carbon grades may be used. Post-weld heattreating is one method for combating sensitization in the HAZ. While a solid solution heat treatment may be used to force the precipitates back into solution, and restore the chemical homogeneity, this is not always possible. This is an acceptable method when the parts may be protected from oxidation and won't be affected by distortion. This is impractical for large structures or field repairs. In these cases an "L" grade should be used.

Fatigue of arc weldments is an area of considerable concern and study. Weld, defects such as porosity and under-cutting, combine with the cast microstructure associated with traditional arc welding and generally decrease fatigue life and corrosion resistance of arc welds. To exacerbate the problem, solidification of the molten weld material induces high residual tensile stresses, while the weld toes (region where the deposited metal meets the base metal) introduce stress concentration points. The combination of these tend to reduce the fatigue life and stress corrosion cracking (SCC) resistance in traditional arc weldments.

\subsubsection{Stress Corrosion Cracking}

Due to the frequent use of austenitic stainless steels in corrosive and elevated temperature environments, the SCC resistance of weldments becomes an important issue. While the addition of ferrite reduces hot cracking problems it simultaneously introduces new problems in austenitic stainless steel weldments. Ferrite contributes to microsegregation and a heterogeneous microstructure, which lead to a weldment that is inferior to the parent material [Ref 7-8]. Stress corrosion cracking problems arise from compositional and metallurgical effects such as inhomogeneous chemistry and austenite-ferrite grain 
boundaries. Residual stresses and weld defects, such as porosity and slag inclusions, further contribute to the SCC problem [Ref 9].

Several researchers have explored the mechanism of SCC cracking in austenitic stainless steel weldments [Ref 1,3,9-11], and have been able to determine the key problems with weldments. It is well known that all welds, both well and poorly executed, will suffer from corrosion [Ref 3,10$]$. This is due to the reasons discussed above and the fact that the segregation of impurities in the boundaries also increases the corrosion rate [Ref 12]. It is also known that an appropriate amount of ferrite needs to be retained; too much ferrite and there will be localized corrosion, too little ferrite and SCC will occur more rapidly [Ref 9].

While there is some disagreement to whether SCC occurs in the austenite or ferrite [Ref $1,3,9,11]$, the same researchers agree that cracking occurs along the path of interdendritic spacing in the weldment. It is logical and has been proven [Ref 11] that when the ferrite network is discontinuous and/or exhibits a small grain size SCC resistance is improved. It has also been shown that corrosion is worse in the weld bead, since the grains, and hence the chemically inhomogeneous interface, are orthogonal to the surface as well as the applied stress [Ref 9]. It is a well-known fact that defects, such as porosity, also decrease the SCC resistance. It is evident that a process that breaks up the ferrite, as well as remove defects, would increase the SCC resistance of austenitic stainless steel weldments and hence, increase the in-service fatigue life of weldments in a corrosive environment.

\subsection{Friction Stir Welding}

Friction stir welding (FSW) is a solid-state joining process that has enabled the joining of previously difficult to weld, or un-weldable, materials. FSW, patented in 1991 by The Welding Institute (TWI) in England [Ref 13-14], has become a vastly researched and advanced process. Countless hours and millions of dollars have been spent in attempts to broaden its range of applications. 
Due to its solid-state nature, FSW, in most cases, produces weldment properties that are remarkably better than those of traditional arc welds. The solid-state nature of FSW produces a final microstructure that is wrought and consists of fine equiaxed grains as opposed to the large-grain cast microstructure typical of an arc weld. Due to the lower heat input associated with FSW, the HAZ properties are an improvement over those of traditional arc welds. Similarly, FSW produces lower residual stresses in the transverse direction and less distortion in the plates after joining [Ref 15-16].

Friction stir welds are produced with a cylindrical rotating tool that consists of a pin and a larger concentric shoulder. The tool is plunged into the joint of the materials to be joined and translated along the interface (Figure 1). As the material is softened by frictional heat, forging pressure from the shoulder reconsolidates the material behind the tool.
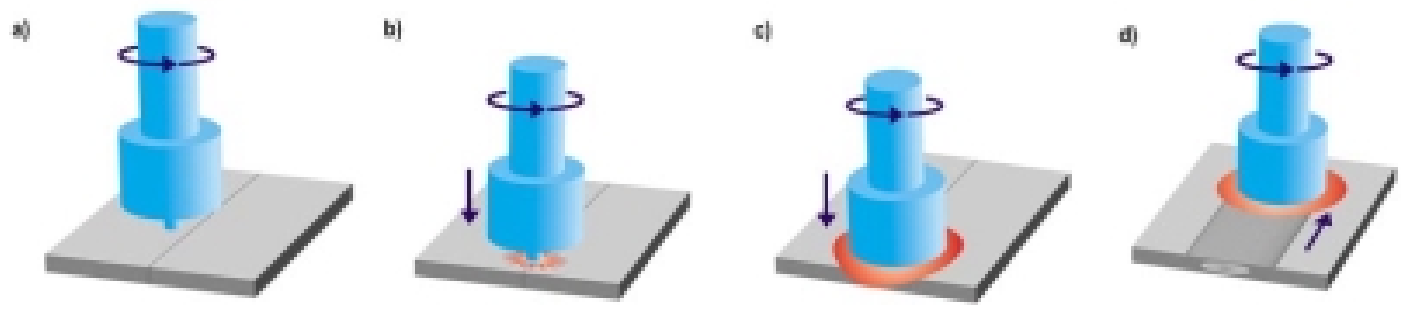

Figure 1. Schematic of FSW

Initially, FSW was applied to high-strength, low-density aluminum alloys that have been traditionally considered to be un-weldable by arc welding. Lippold and Ditzel recently reviewed the literature for FSW of aluminum alloys [Ref 17]. They reported that FSW was capable of achieving joint efficiencies of up to $95 \%$ in aluminum alloys. They also summarized the characteristic microstructures achieved through FSW.

Researchers have also found it feasible to join other low temperature materials (LTM), such as copper, with good success. In one study, the authors investigated the feasibility of FSW nuclear waste containment vessels made of corrosion resistant copper [Ref 18]. 
FSW of LTM is showing substantial increases in weld quality and reduction in cost. Therefore, it should be advantageous to implement FSW in joining steels and other high temperature materials (HTM) as well. Generally, steels are much more weldable than aluminum and may be welded very quickly.

Steels account for a large majority of the welded product worldwide. In fact, one report indicates that the percentage of steel welded vs. other materials in shipyards is $96 \%$ [Ref 19]. While these numbers are undoubtedly skewed by the nature of ship building, they do indicate the disproportionate nature of aluminum vs. steel welding. The sheer volume of welded steel in industry makes it desirable to introduce the benefits of FSW in this new arena. While LTM have been easily joined using tools made of hardened tool steel, it has become clear that in order to join HTM, new tool materials need to be developed to withstand the higher temperatures.

\subsubsection{FSW Tool Materials}

Initially commercially pure (CP) tungsten was used as a tool material for FSW of HTM. It was soon noted that the CP tungsten would wear and deform dramatically during the welding process [Ref 20]. Tungsten rhenium (W-Re) soon became the tool material of choice for many researchers. While the tools have been able to produce good quality welds, W-Re tools have not produced suitable tool life to justify their use as FSW tools for HTM in a production environment [Ref 20-23]. Studies continue to improve the composition and properties of W-Re in an effort to make it a more viable material for FSW HTM.

Polycrystalline cubic boron nitride (PCBN) is a synthetic super abrasive, which is second only to diamond in hardness. Due to its excellent chemical stability and elevated temperature wear resistance, PCBN been used as a cutting tool for nickel-based super alloys, high strength ferrous materials, and cast irons. 
PCBN has been used and proven to be a viable tool material for FSW HTM at Brigham Young University ${ }^{1}$. PCBN has been used successfully to join nickel-based alloys, austenitic stainless steel, low carbon steel, quenched and tempered carbon manganese steel, high strength-low alloy (HSLA) steels, and duplex stainless steels. Results have been very promising and the tensile strength of welds has approached, and in some cases, exceeded the base metal properties. Furthermore, tool life with PCBN tools is excellent and has been determined to be capable of producing 80 linear meters of sound welds [Ref 24-30].

\subsection{Friction Stir Processing}

A variation of FSW, called friction stir processing (FSP), uses the same general setup and tools as FSW, but is used to selectively modify the microstructure of materials to enhance specific properties. Mahoney et al reported FSP to be useful in producing a suitable microstructure for high-strain rate superplasticity in 5mm thick $7075 \mathrm{Al}$ [Ref 31]. Optimum superplasticity is achieved when small equiaxed grains, separated by high angle boundaries, exist homogeneously throughout the strained region. Both of these characteristics are present in the as-processed condition following FSP. Similarly, Miles et al found FSP useful in thick section bending of $25 \mathrm{~mm}$ thick 2519 Al [Ref 32].

$\mathrm{Su}$, et al [Ref 33-34] have reported the ability of FSP to create nanocrystalline microstructures in $7075 \mathrm{Al}$ with an average grain size of $100 \mathrm{~nm}$. They further reported that by changing process parameters and cooling rates they could control the average grain size. While nanostructured materials have proven valuable, this study showed FSP as a viable method for decreasing manufacturing costs and increasing the possibility to scale up production of bulk nanocrystalline material.

FSP has also been shown useful in eliminating the cast microstructure of Ni-Al bronze. It was found that FSP homogenized and refined the grain size, while eliminating porosity

\footnotetext{
${ }^{1}$ PCBN tooling was developed in cooperation with Advanced Metal Products (Scott Packer) and Smith MegaDiamond Inc.
} 
and inclusions. In effect, FSP changed the cast microstructure to a wrought microstructure, which increased the tensile and yield strength, fatigue life, and corrosion resistance [Ref 35]. Similarly, Mahoney and co-workers found FSP beneficial in modifying the microstructure in cast aluminum alloys [Ref 36].

Fatigue life in arc welded $5083 \mathrm{Al}$ was also increased via FSP [Ref 37]. Sound arc welds were produced in $25 \mathrm{~mm}$ thick $5083 \mathrm{Al}$. Some welds were then FS processed at the weld toes while others were FS processed across the entire weld crown. It was seen that the fatigue life of the FS processed welds was higher than that of the as-welded plates. It was also interesting to note that the scatter in the fatigue data was reduced in the FS processed conditions. This was due to the homogenization and reduction in porosity from FSP.

\subsubsection{Friction Stir Processing Stainless Steel}

In a preliminary feasibility study, the author has found FSP useful in eliminating the cast microstructure in autogenous (without filler material) arc welds in austenitic stainless steel. A transverse cross section, of an FS processed autogenous arc weld in 316L stainless steel is shown in Figure 2. The dark, heavily etched region is the arc weld. The lighter areas on either side of the arc weld are where FSP occurred. While FSP did not remove the delta-ferrite, it broke it up into smaller discontinuous particles. In addition, FSP refined the coarse grain size of the arc weld. Figures $3 \mathrm{a}$ and $3 \mathrm{~b}$ below indicate the dramatic difference.

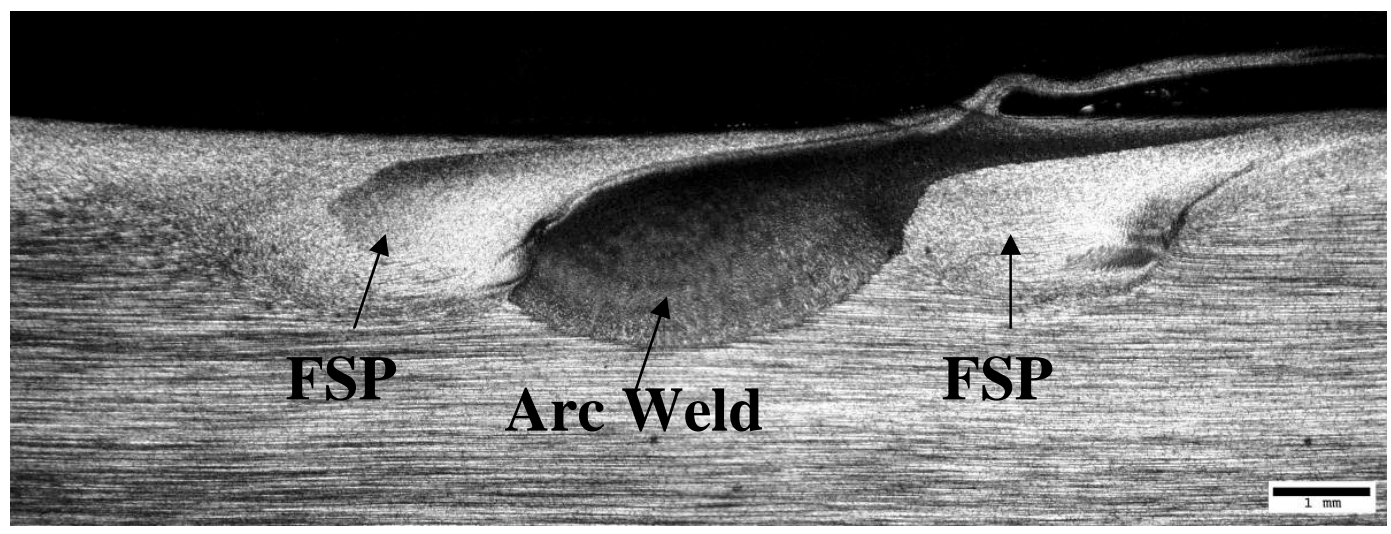

Figure 2. Cross section of FSP in 316L autogenous weld 


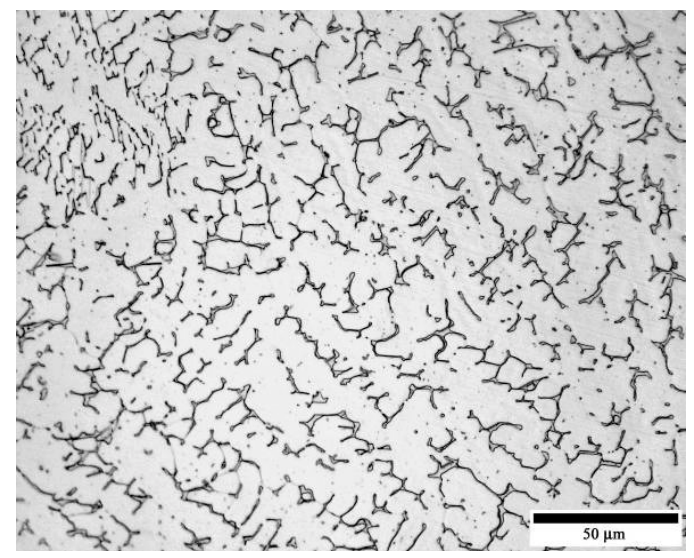

a)



b)

Figure 3. Photomicrographs of a) arc welded 316L and b) FS processed zone

This reduction in grain size in FS processed austenitic stainless steel weldments should be beneficial for two reasons. First, from the Hall-Petch effect [Ref 38-39] the strength of the material increases with the refining of grain size. Second, the smaller grain size should also inhibit crack initiation, crack growth rate and stress corrosion cracking. Unpublished work in FS welded and FS processed 304L stainless steel produced a macrostructure typical of that found in aluminum (Figure 4). The processed material exhibited a SZ, thermo-mechanically affected zone (TMAZ), and HAZ. However, the TMAZ only showed the typical elongated up-lifted grains at the advancing side of the microstructure. The retreating side was much less distinct.

All of the processing parameters created a concentration of a second phase at the lower advancing side of the tool (black arrow). This phase generally appeared as alternating bands. Park et al identified the second phase, as the sigma phase [Ref 40]. As discussed below, the sigma phase is detrimental to both corrosion and fatigue. Therefore, it would be desired to process at parameters which would minimize the percentage of sigma and limit its location to sub-surface. 


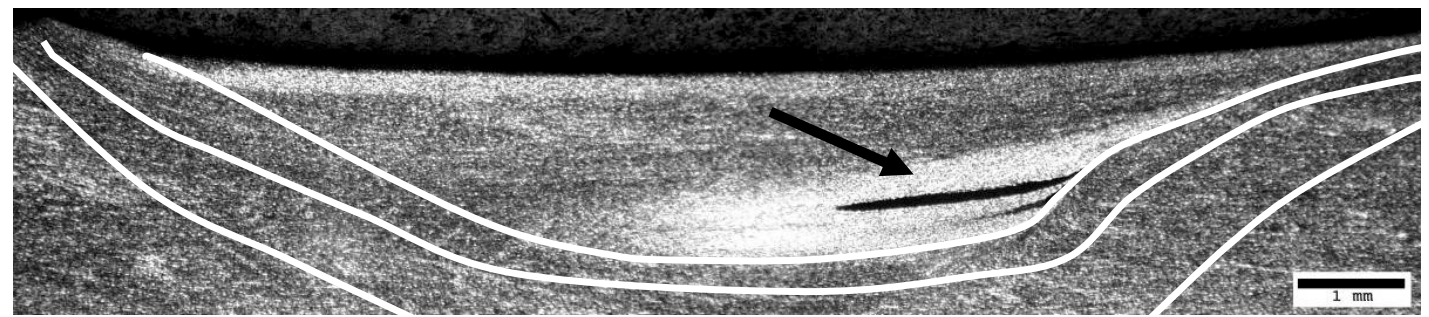

Figure 4. Typical FSP zone, shown from section processed at 800 RPM and $50 \mathrm{~mm} / \mathrm{min}$

The unpublished work further indicated that tool rotation and travel speed had a significant effect on the resulting microstructure and location and percentage of sigma in the material (Figure 5). While all parameters investigated produced some amount of sigma, some produced sigma nearer the surface than others. Based on the quality of the resulting microstructure and surface finish of the processing, it appeared that FSP 304L with PCBN tools would create the best surface finish and the least amount of sigma at $400 \mathrm{rpm} 50 \mathrm{~mm} / \mathrm{min}$ and a load of $40 \mathrm{kN}$.

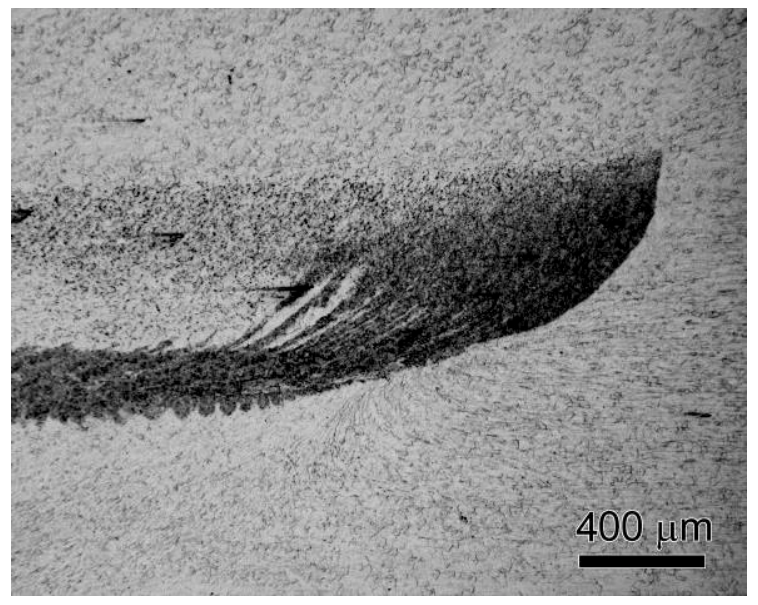

a)

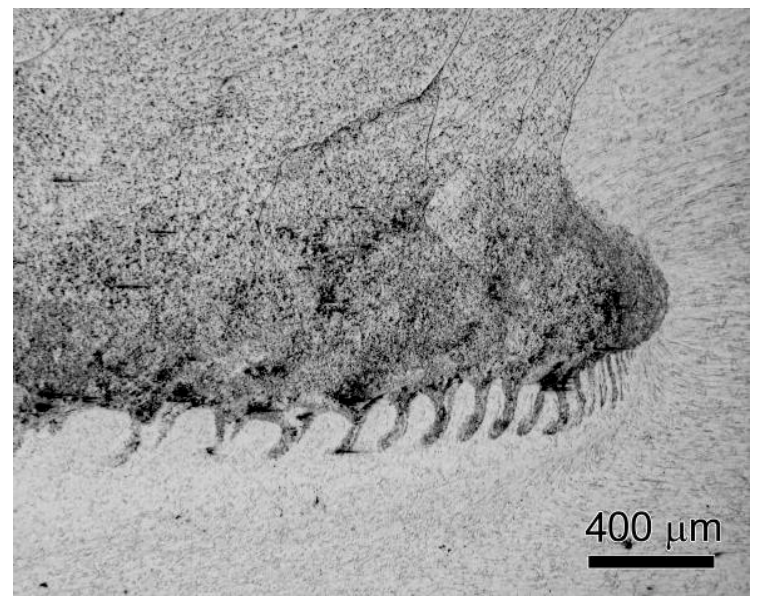

b)

Figure 5. Optical macrographs indicating the effect of processing parameters on resulting microstructure in 304L stainless steel a) processed at $400 \mathrm{rpm}$ and $50 \mathrm{~mm} / \mathrm{min}$ b) processed at 800 rpm and $130 \mathrm{~mm} / \mathrm{min}$ 


\subsubsection{Sigma}

Sigma is an intermetallic phase that may form from the transformation of delta ferrite in austenitic stainless steels when the temperature is held above $500{ }^{\circ} \mathrm{C}$ for long periods of time. One study has indicated that sigma phase precipitates first on triple points then on grain faces. It may also form on incoherent twin boundaries and intragranular inclusions when held at high temperatures for long periods of time. The $50 \% \mathrm{Cr} 50 \% \mathrm{Fe}$ composition of sigma depletes the surrounding areas of chrome, creating a microstructure more susceptible to corrosion. Furthermore, sigma is very hard and brittle; the combination of this, and its poor corrosion resistance, reduces the fatigue life and SCC resistance of materials when sigma is present [Ref 41].

\subsection{Hypothesis}

It is the author's belief that FSP may be applied as a method to decrease the grain size, porosity, length of ferrite stringers, continuity of the ferrite stringers, and the orthogonal nature of the ferrite stringers to the applied stresses in austenitic stainless steel weldments. The improvements achieved will create a type of microstructure that has been proven to increase the SCC resistance and fatigue life in a corrosive environment of stainless steel arc welds. 


\section{Method}

\subsection{Overview}

Sound arc welds were produced in $12 \mathrm{~mm}$ thick 304L and subsequently FS processed at the crown and the root of the weld. Following comprehensive metallographic evaluation of the FS processed arc welds, samples were removed for microhardness mapping as well as tensile and fatigue testing.

\subsection{Arc Welding}

Full penetration arc welds were produced in $12 \mathrm{~mm}$ thick $304 \mathrm{~L}$ with a nominal composition in weight percent of $0.03 \mathrm{C} \max , 2.0 \mathrm{Mn}, 0.75 \mathrm{Si}, 8.0-12.0 \mathrm{Ni}, 18.0-20.0 \mathrm{Cr}$, $0.1 \mathrm{~N}, 0.03 \mathrm{~S}, 0.045 \mathrm{P}$, and the balance Fe (Figure 6). The edges of the plates were beveled to have a $60^{\circ}$ included angle. The plates were flux core arc welded with 308 stainless steel filler material, which results in a dual phase austenite matrix containing 20$25 \%$ delta ferrite. Using 308 filler material resulted in a stronger weld bead than the base material commonly referred to as an overmatched weld. Due to the thickness of the plate a root pass was performed, followed by several more passes, to fill the grove and produce a crown.

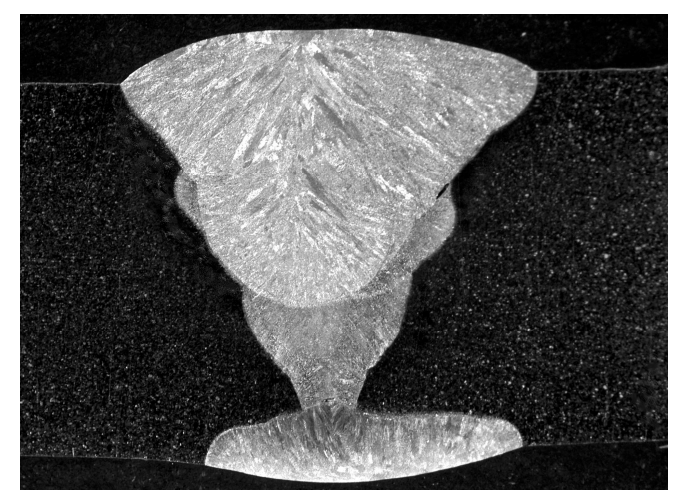

Figure 6. Cross section of $304 \mathrm{~L}$ arc weld produced with 308 filler material 


\subsection{Friction Stir Processing}

FSP was performed on a custom designed and built CNC vertical mill producing 30 horsepower, allowing the process to be controlled by the rotation rate of the tool, the linear travel speed of the tool, and the vertical force on the tool.

The tool material used was PCBN. The tool had a $25 \mathrm{~mm}$ diameter shoulder with a pin length of $3.2 \mathrm{~mm}$ (Figure 7a). Due to the high temperatures encountered, a liquid-cooled tool holder produced by Tecnara was used to minimize heating of the machine's spindle bearings (Figure 7b). Ethylene glycol refrigerated in a commercial recirculating cooler was passed through the tool holder at a temperature of $11^{\circ} \mathrm{C}$.

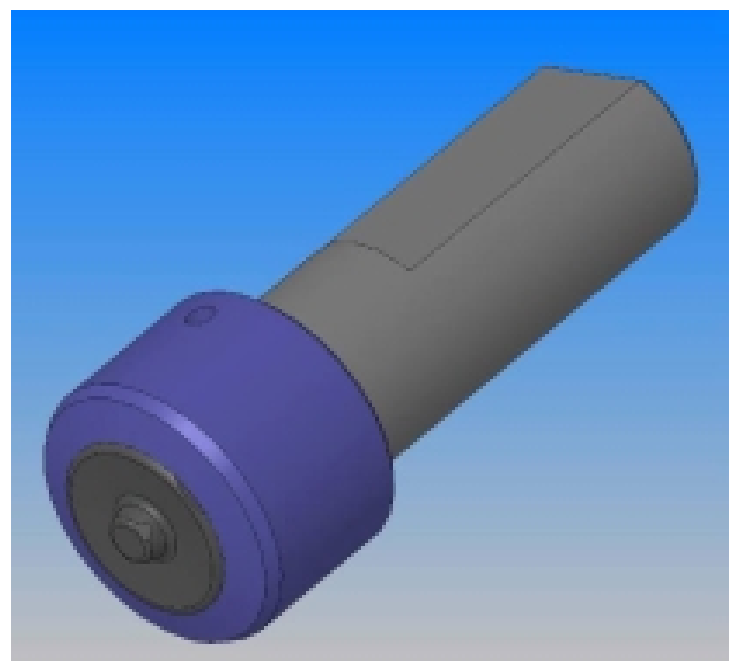

a)

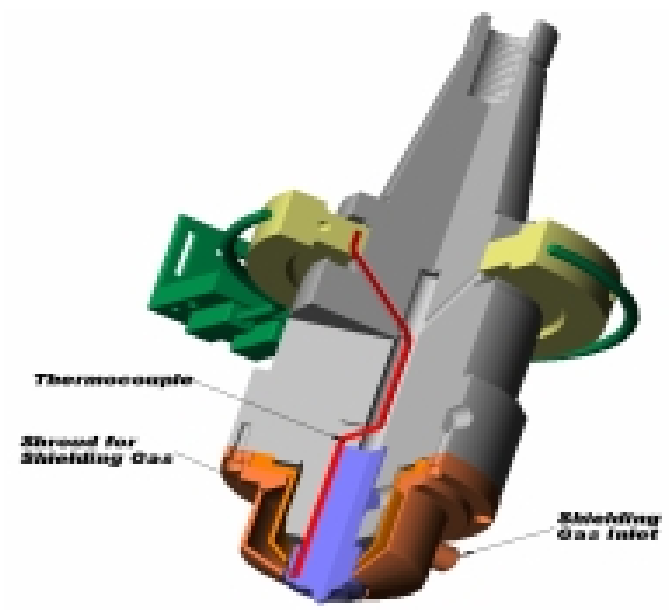

b)

Figure 7. a) Tool drawing and b) illustration of liquid cooled tool holder and telemetry thermal couple systems

The parameters previously found suitable for FSP plate $(400 \mathrm{rpm}, 50 \mathrm{~mm} / \mathrm{min}$, and $40 \mathrm{kN}$ load) were used to FS process the arc welds. The root and crown of the arc welds were machined prior to processing, to leave a flat surface and remove heavy oxides formed during the welding process. The crown was processed two times to cover the width of the weld zone. Each time the advancing side of the tool was situated toward the center of 
the arc weld. The root was processed in a single pass with the tool centered on the weld line.

\subsection{FS Processed Arc Weld Evaluation}

\subsubsection{Microstuctural Evaluation}

Cross sections were removed transverse to the welding direction for metallographic, microhardness, and mechanical property characterization. Metallography and phase identification was aided by the use of a modification of Murakami's reagent [Ref 42]. Orientation imaging microscopy $\left(\mathrm{OIM}^{\mathrm{TM}}\right)$ was used to help identify the phases in the samples.

Once distinct regions were identified by optical metallography, a $3 \mathrm{~mm}$ diameter cylinder was cut out of the lower portion of the stir zone (SZ) for observation with a transmission electron microscope (TEM) (Figure 8). The sample was removed and sectioned with an electron discharge machine prior to mechanical thinning and final thinning via a twin jet electro-polisher, using a solution of $10 \% \mathrm{HClO}_{4}$ and $90 \%$ methanol. The samples were observed with a JEOL 2000 FX TEM at $200 \mathrm{kV}$.

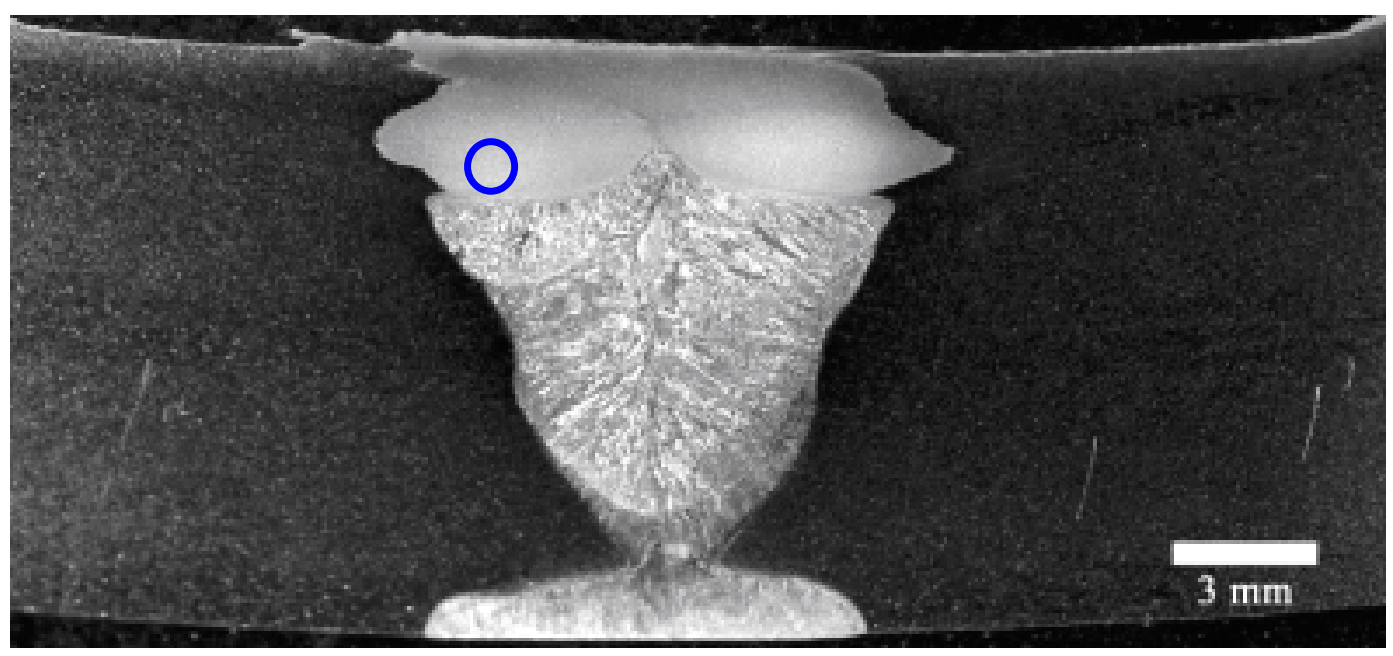

Figure 8. TEM sample location 


\subsubsection{Mechanical Property Evaluation}

A full microhardness map of a representative sample was produced; this sample was indented and measured in the as-polished condition.

Tensile samples were removed from the arc weld, and the FS processed arc weld. The welds and FS processed samples were tested transverse to the welding direction. Samples were mechanically tested in accordance with ASTM E-8. A servo-hydraulic MTS tensile machine with $100 \mathrm{kN}$ load capacity was used. Elongation was measured via a $50 \mathrm{~mm}$ extensometer.

Fatigue testing was carried out for the arc welds and the FS processed arc welds. Four point bending was used in order to apply a constant stress across the weld crown and FS processed region. Arc welds were tested in the as-welded condition. In order to eliminate the effect of the weld toes, and focus on microstructure, arc welds and FS processed arc welds were tested after being finely ground. The samples were machined to $25 \mathrm{~mm}$ wide samples by $12.5 \mathrm{~mm}$ thick for testing. The testing, on FS processed samples and arc welds with the crown ground flat, began at $550 \mathrm{MPa}$ and was decreased in $70 \mathrm{MPa}$ increments to a final load of $270 \mathrm{MPa}$. The as-welded arc welds were tested from $410 \mathrm{MPa}$ down to $120 \mathrm{MPa}$. Metcut in Cincinnati, Ohio carried out the testing on a Warner \& Swasey SF-01-U constant force sinusoidal fatigue tester. 


\section{Results and Discussion}

\subsection{Macrostructural Comparison of FS Processed Arc Welds vs. FS Processed Base Material}

The overall geometry of the FS processed arc welds was very similar to the geometry that has been observed in FS welded and processed 304L base material. These include a sharp transition from the SZ to the base metal on the advancing side of the structure and a less distinct transition on the retreating side (Figure 9a). Despite these similarities, there were some fairly obvious differences as well.

A distinct interface visually divided the $\mathrm{SZ}$ into an austenitic region (AR) and a multiphase region (MPR). The AR and MPR are outlined in the second FS processed pass in Figure 8a by solid and dashed white lines, respectively. The well-defined boundary between the AR and MPR occurs near the retreating side of the pin tool (Figure 9b). The composition of the MPR and AR is largely due to the initial composition of the weld nugget and base metal respectively.

Some FSW researchers have defined the "flow arm" in an FS weld as the upper region of the SZ, where material is swept by the tool shoulder from the retreating side of the processed zone to the advancing side. Some austenite from the base metal has been swept across the initial fusion boundary over the upper portion of the MPR by the flow arm. Similarly, a small amount of ferrite has been swept into the bottom region of the MPR apparently forcing some of the MPR to "extrude" towards the AR past the initial fusion boundary. The nature of the "flow" of material during FSW and FSP continues to be a topic of much debate among FSW researchers. Some have suggested that material "sticks" to the pin tool or is stirred several times before being deposited in a completely different location from its origin. The lack of mixing between the original austenitic and 
dual-phase regions in FS processed 304L arc welds indicates that material movement occurring during FSP and FSW is minimal and may be due to an extrusion type process.

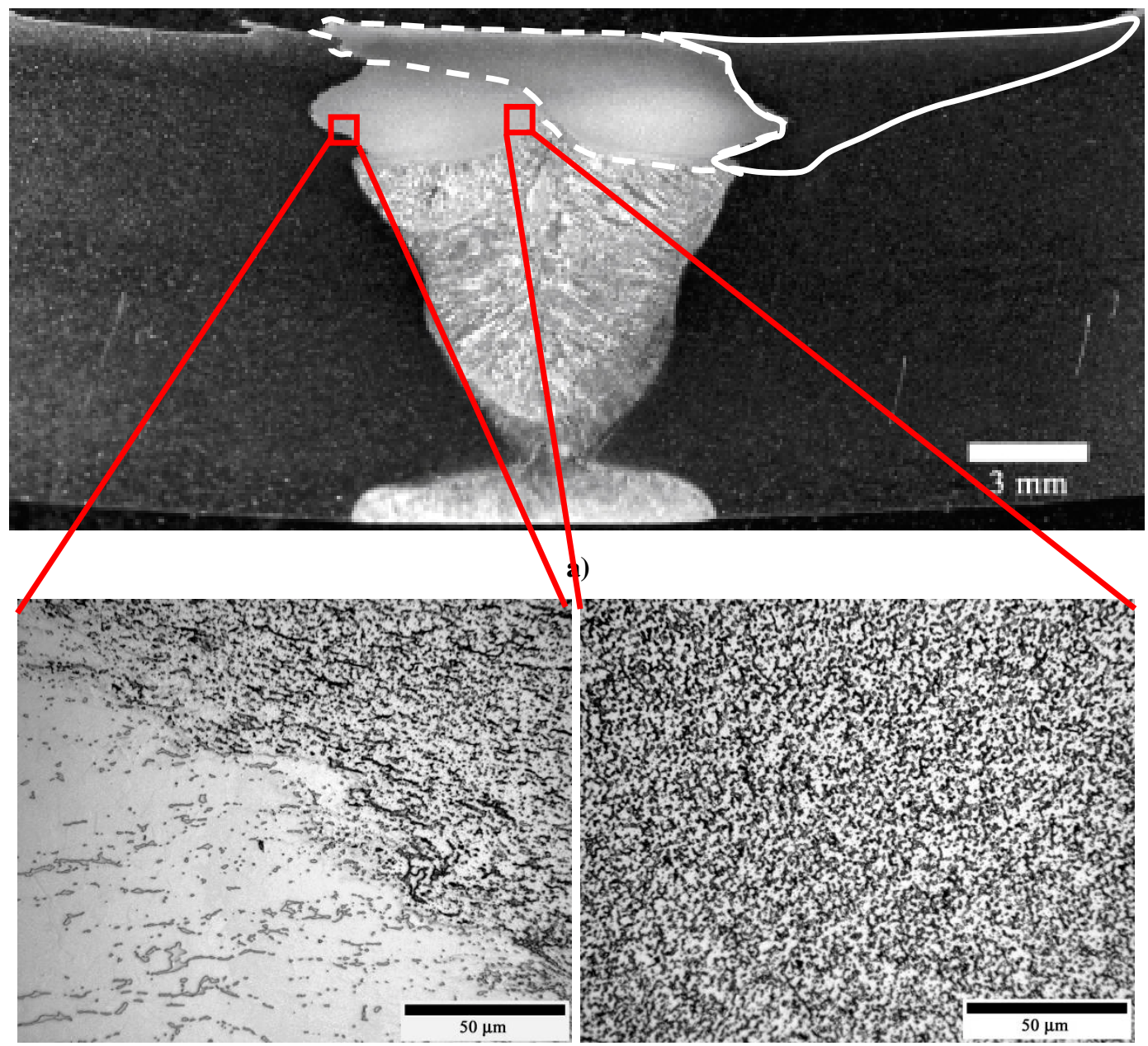

b)

c)

Figure 9. a) Transverse macrophotograph showing general structure of FS processed 304L arc welds b) micrograph showing sharp difference between austenite and multi-phase region c) edge of advancing side SZ, lacking elongated uplifted grains

Another obvious difference was the lack of heavy banding at the lower advancing side of the SZ that was evident in the FS processed base metal (Figure 5). Initially, this gave the impression that sigma had not been produced during FSP. However, after detailed analysis, it was determined that sigma was present. This topic will be discussed in greater detail in section 3.4. 
The structure of the TMAZ in FS processed 304L arc welds was different from the FS processed base material in that it lacked evidence of elongated up-lifted grains (Figure 9c). The difference in the visible deformation of the TMAZ is likely due to the fact that this phenomenon is hard to track in the fine grain equiaxed microstructure produced from the initial FS processed pass. In a rolled microstructure the elongated grains are "pinned" on one end by surrounding grains. In spite of this, near the pin tool the grains tend to deform upward. Post-weld analysis allows one to observe both the final position of the deformed end and the initial "pinned" position of the grain. In a fine grained microstructure, the grains likely deform and move. However, the lack of an archive indicating their original position gives the appearance that no deformation has occurred in the TMAZ.

Initial results from FS processed arc welds indicated that the flow arm could be utilized to move the single phase austenite of the base metal over the arc weld nugget, decreasing the amount of dual phase material exposed to the surface (Figure 2). It is known that a large area of dual phase material exposed to the surface of an arc weld provides a susceptible microstructure with regards to SCC. In an attempt to sweep austenite across the weld metal with the flow arm, FSP was performed with the advancing side of the tool towards the center of the weld. The processed zone of the second FS processed pass exhibited a large flow arm, where the dual phase material of the arc weld was swept by the shoulder across the top of the first FS processed pass (upper left portion of MPR as shown in Figure 9a). Likewise, a smaller flow arm was evident at the upper left side of the AR as austenite was pulled across a portion of the MPR. This reduced the exposed surface area of the MPR, compared to the original exposed surface area of the dual phase arc weld by $30 \%$. This decrease in the exposed surface area of the MPR should reduce the number of sites where SCC may initiate.

As expected, FSP altered the microstructure of the arc weld significantly. The ferrite stringers were no longer continuous, but had been broken up into finer, discontinuous particles with an average diameter of $4 \mu \mathrm{m}$, as discussed in greater detail in a later section. FSP also eliminated voids and porosity, which typically exist in arc welds, creating a 
fully-consolidated fine grain equiaxed microstructure at the surface of the arc weld (Figure 9a).

\subsection{Surface Finish}

Processing 304L arc welds with parameters that had been successfully used for FSW $304 \mathrm{~L}$ provided challenges that had not been expected. The primary difference was in the surface finish of FS processed arc welds. The finish was no longer smooth and silvery (Figure 10a), rather it was somewhat rough and oxidized (Figure 10b). Since this surface finish is a concern with regards to corrosion and fatigue, varying parameters were explored in an attempt to minimize the problem. Although parameters were found that produced acceptable results, the rough, oxidized surface finish was undesirable.

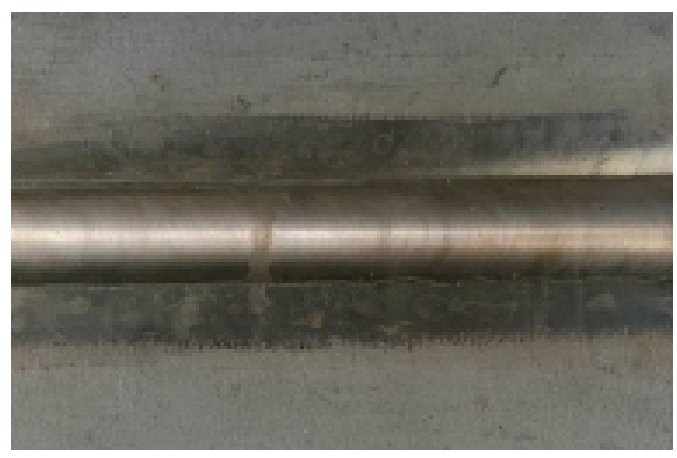

a)

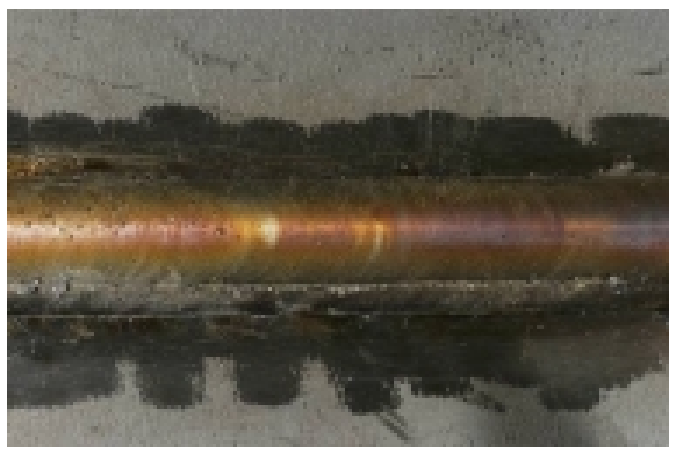

b)

Figure 10. Photographs showing FSP surface finish in a) 304L plate and b) arc welded 304L plate

The most obvious difference in processing base material and arc welds was the change from a single phase austenitic material to a dual phase austenitic-ferritic material. Hypothesizing that the surface finish difficulties stemmed from this difference, it was decided to FS process a single phase austenitic arc weld. Subsequent FSP of a 304L arc weld joined with fully austenitic 310 stainless steel filler material produced a smooth surface finish similar to that of FS processed base material (Figure 11). From this, it was determined that the dual-phase nature of the 304L welds produced with 308 filler material was responsible for the poor surface finish. 


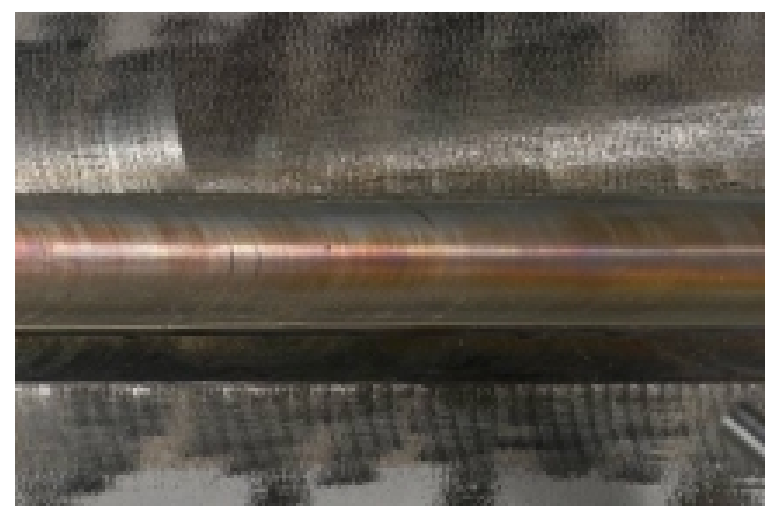

Figure 11. Surface finish in FS processed 304L stainless steel welded with austenitic filler material

The exact reason why the dual-phase nature causes this phenomenon has not been studied in detail. However, it is a well known fact that ferrite and austenite have significantly different mechanical properties. Specifically, it is known that ferrite has a higher flow stress than austenite. It is also known that suitable FSW parameters vary according to the properties of the materials being joined. Therefore, it is the opinion of the author that the surface finish difference encountered when FSP 304L arc welds is related to the different flow stresses of the austenite and ferrite in the arc weld.

\subsection{Microstructure Comparison}

\subsubsection{Austenitic Region Microstructure}

Figures $12 \mathrm{a}$ and $12 \mathrm{~b}$ indicate that a reduction in grain size throughout the AR of the SZ, compared to that of the base metal, was achieved through FSP. OIM ${ }^{\mathrm{TM}}$ was utilized to confirm this optical observation. The majority of the grains (measured by area fraction) in the AR of the SZ exhibited a grain size in the range of $20-35 \mu \mathrm{m}$, while the majority of the grains in the base metal exhibited a grain size in the range of $25-45 \mu \mathrm{m}$. These ranges appear to be nearly identical. However, approximately $12 \%$ of the area fraction of the AR exhibited grains with a diameter $10 \mu \mathrm{m}$ or less, while only $4 \%$ of the area fraction of the base metal exhibited grains with diameter $10 \mu \mathrm{m}$ or less (Figures 12c, 12d). The higher percentage of grains smaller than $10 \mu \mathrm{m}$ in the AR compared to the base metal results in a significantly different average grain size between the two areas. The AR 
exhibited an average grain size of $3 \mu \mathrm{m}$ while the average base metal grain size was nearly five times larger at $14 \mu \mathrm{m}$.

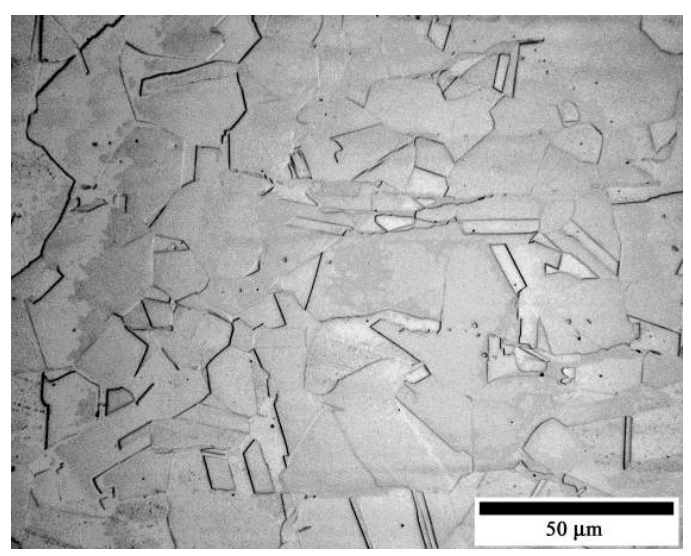

a)

Grain Size (diameter)

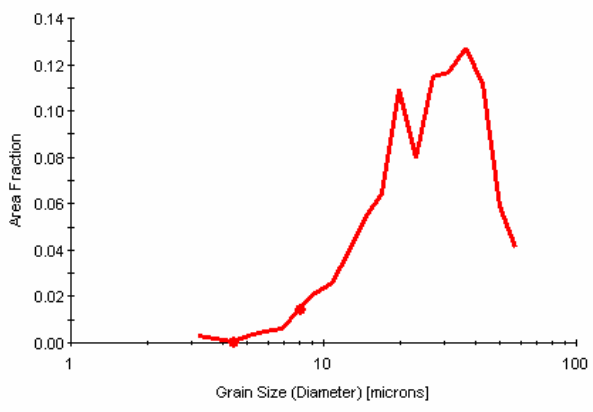

c)

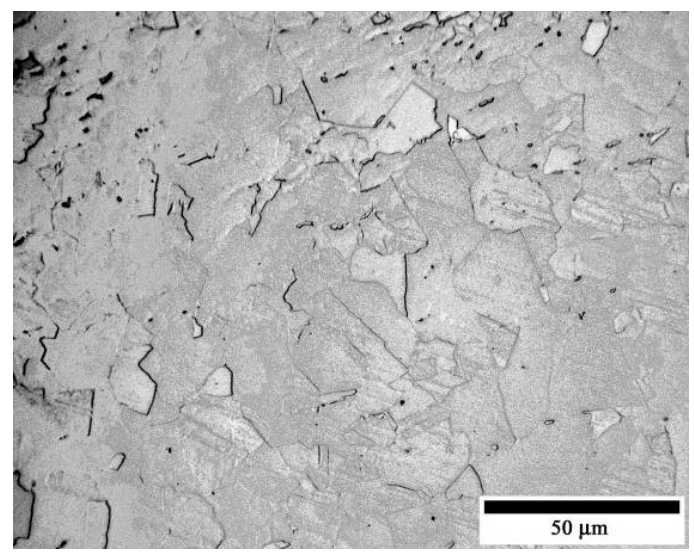

b)

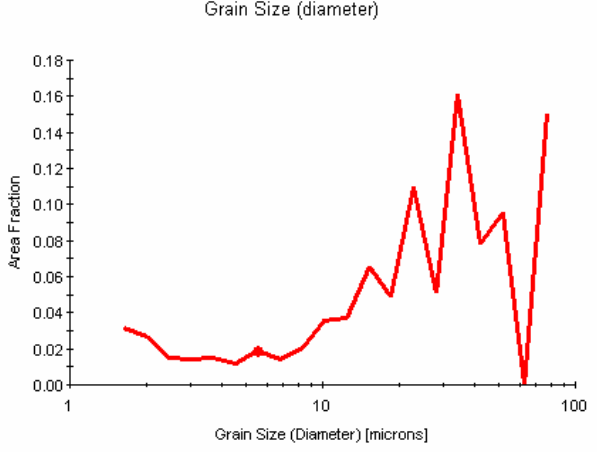

d)

Figure 12. Photomicrographs of a) unaffected base metal and b) retreating side of an FS processed 304L arc weld and OIM ${ }^{\mathrm{TM}}$ results showing the grain size distribution in c) unaffected base metal and d) retreating side of an FS processed 304L arc weld3.3.2 Multi-phase Region Microstructure

\subsubsection{Multi-phase Region Microstructure}

The microstructure in the MPR of the SZ was significantly different than the microstructure in the arc weld metal. OIM ${ }^{\mathrm{TM}}$ results indicate that while the amount of ferrite in the arc weld and the MPR remained roughly the same, the morphology had changed significantly. The ferrite in the arc weld consisted mostly of vermicular and lacy ferrite (Figure 13a). In contrast, the MPR exhibited fine equiaxed islands of ferrite within 
the refined austenite matrix (Figure 13b). While not shown here, OIM ${ }^{\mathrm{TM}}$ showed that the ferrite exhibited a slightly smaller grain size than the austenite. The average grain size of the austenite was $\sim 8 \mu \mathrm{m}$, while the ferrite was $50 \%$ smaller at $\sim 4 \mu \mathrm{m}$. A similar difference in grain size has been reported by researchers studying FSW of duplex stainless steels [Ref 43]. While studies have not been completed to explain this difference, it is hypothesized that the difference stems from the unique microstructural evolution of the two phases during FSP and FSW.

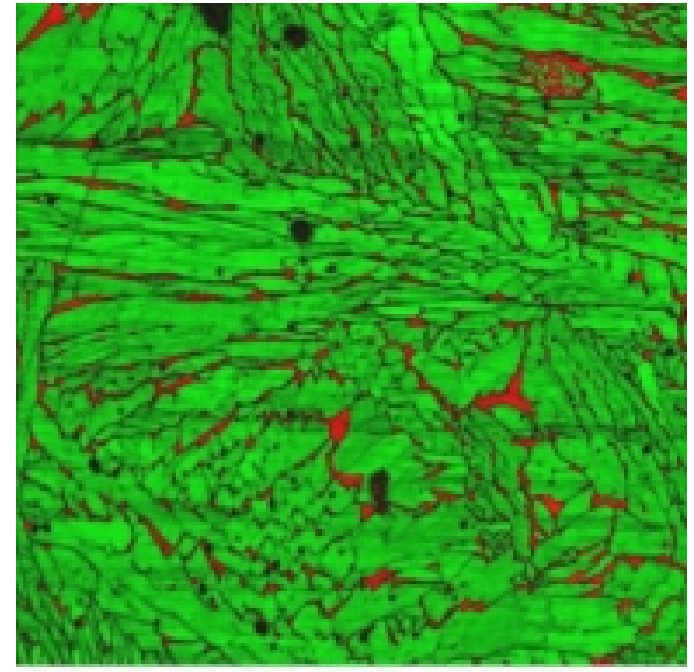

$60.00 \mu \mathrm{m}=60$ steps 10 13.165. 71.905. Phase

a)

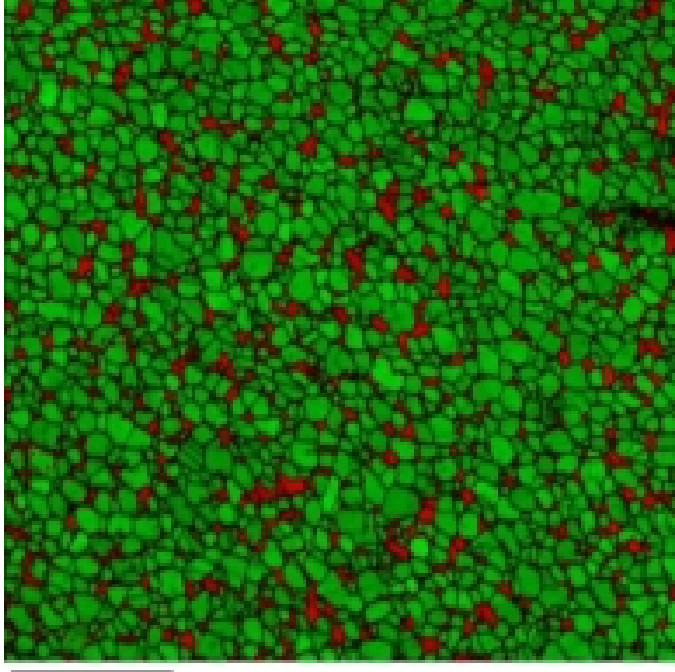

$60.00 \mu \mathrm{m}=60$ steps 10 16.498_.68.91, Phase

b)

Figure 13. OIM ${ }^{\mathrm{TM}}$ maps showing the phase morphology in a) the arc weld (austenite is green, ferrite is red) and b) the FS processed arc weld

\subsubsection{General Stir Zone Microstructure Improvements}

Arc welding typically produces a microstructure which is void of twins. While twins are not a necessity, they do create a more favorable microstructure for many mechanical properties. An important microstructural advantage gained through FSP 304L arc welds was the introduction of twin boundaries throughout the SZ. The percentage of twin boundaries in the FS processed areas was roughly $50 \%$ of the twin percentage of the base metal. While the lower percentage of twins in the SZ compared to the base metal is undesirable, their presence is certainly an improvement over the arc weld microstructure. 
Interestingly, there was no correlation between twin boundary percentages and the location within the SZ, even between the AR and MPR. This suggests that the microstructural evolution of the austenite is only a function of the austenite itself and not the surrounding phases. While the overall area fraction of twins was lower in the MPR than the AR, the ratio of twin boundaries to the total number of austenite boundaries in these regions was nearly identical. OIM ${ }^{\mathrm{TM}}$ results indicate that the twin boundary percentage ranged from $10-16 \%$ throughout the FS processed region.

At the top surface of the MPR, near the tool shoulder, another microstructural improvement was observed. In arc welds, the molten weld pool solidifies from the base metal towards the center of the weld nugget. As the nugget continues to solidify, grains grow in a columnar fashion turning upward near the weld center, becoming nearly perpendicular to the weld surface at the weld crown (Figures 14a, 14b). In 304L stainless steel welds, the weld pool solidifies as primary ferrite. As the weld continues to cool, the majority of the ferrite transforms to austenite.

Ferrite, which is rich in chromium, depletes the surrounding austenite of chromium creating a chemical inhomogeneity. This generally leaves the austenite along the austenite-ferrite boundary less corrosion resistant. Differences in chemical resistance, along with impurities along the austenite-ferrite interface, create preferential sites for corrosion to rapidly initiate. Furthermore, at the weld surface, the grain boundaries are almost always perpendicular to the applied stresses. The resulting chemical inhomogeneity and orientation of the grains create a structure susceptible to SCC.

FSP created a more SCC resistant microstructure near the surface of the MPR than that present in arc welds. Instead of the ferrite being perpendicular to the surface, the ferrite was broken up and oriented parallel to the surface (Figure 14c). Furthermore, the ferrite became more discontinuous in nature than the initial ferrite stringers. Similar microstructural refinements were also observed in the AR of the SZ (Figure 14d). As discussed previously, these are characteristics of a more SCC resistant material. 


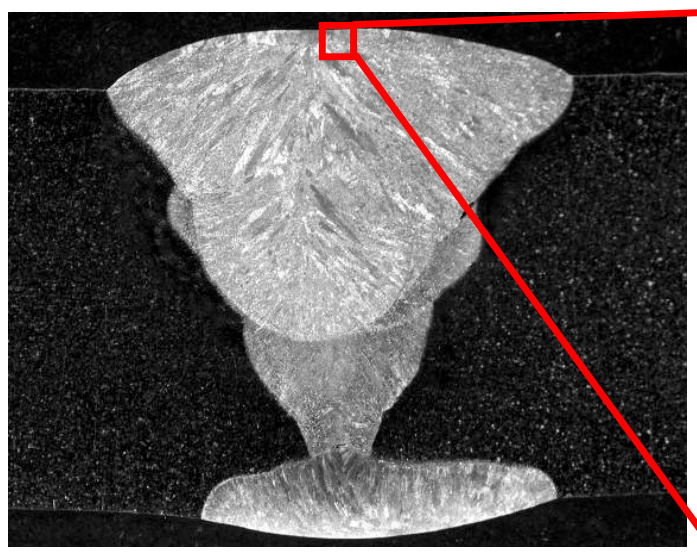

a)

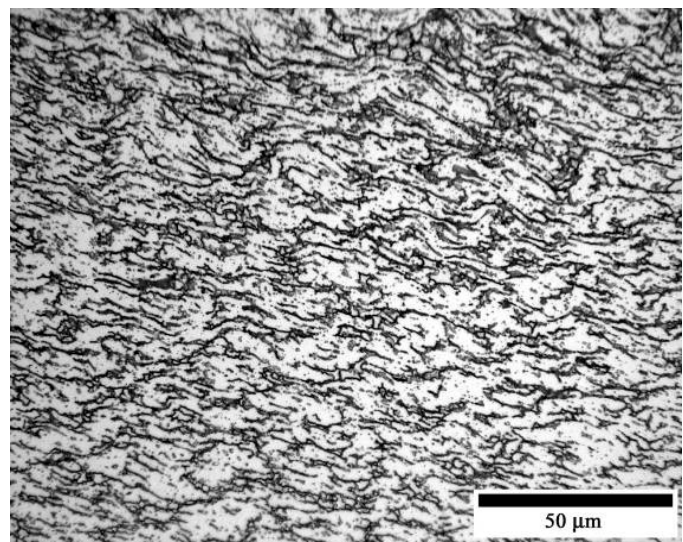

c)

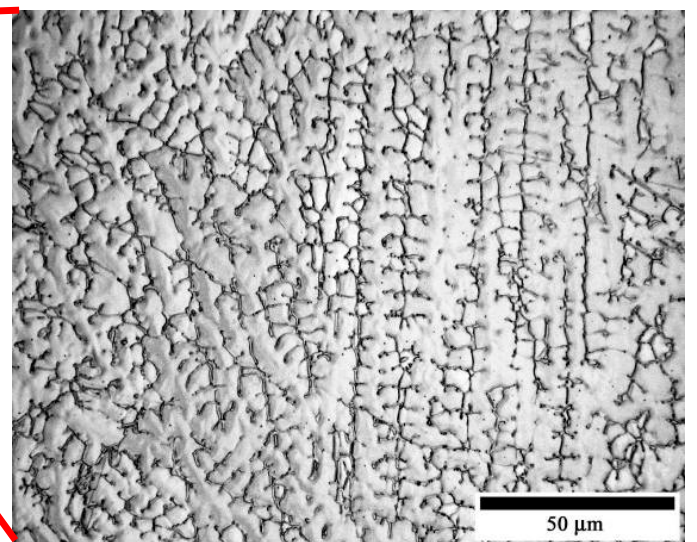

b)

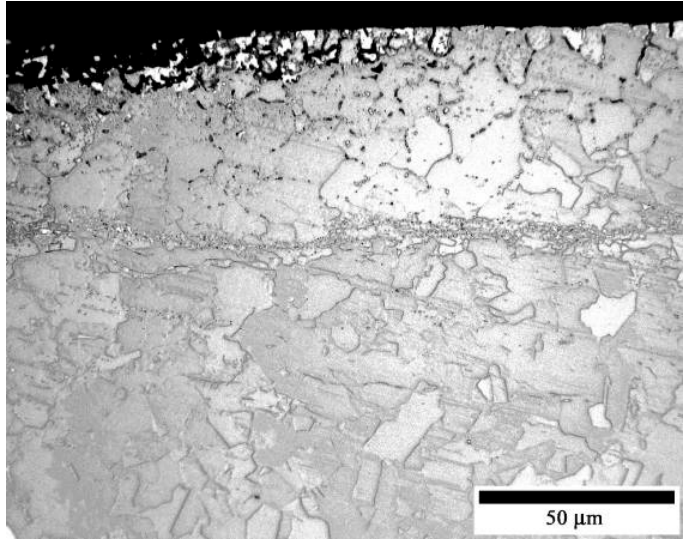

d)

Figure 14. Photographs showing a) macro of an arc weld before FSP $b$ ) the top surface of the arc weld prior to FSP c) top of the advancing side $\mathrm{SZ}$ and d) top of the retreating side $\mathrm{SZ}$

\subsection{Adverse Phases}

Sigma has previously been reported in FS welded and FS processed 304L stainless steel [Ref 40]. Due to its detrimental corrosion properties, it was important for the author to determine whether or not sigma was present. While sigma banding was not evident in samples etched with oxalic acid, careful microstructural evaluation indicated the presence of sigma. Employing optical metallography and a modification of Murakami’s reagent, the author was able to delineate the austenitic matrix from the sigma and ferrite. A sample photomicrograph is shown in Figure 15a where sigma is observed as a bright blue color (indicated by arrows), austenite white, and ferrite yellow/brown. Further work using the TEM indicated that small particles, matching the size and morphology reported by Park et al [Ref. 40] as sigma, were present in the FS processed arc welds (Figure 15b). 
The SEM was utilized in its backscatter configuration to identify the concentration of sigma in various locations within the SZ. The greatest concentration of sigma was primarily located in the lower advancing side of the FS processed region (Figure 15c, 15d). The combination of these proven methods allowed the author to confirm that sigma was present in FS processed 304L arc welds.

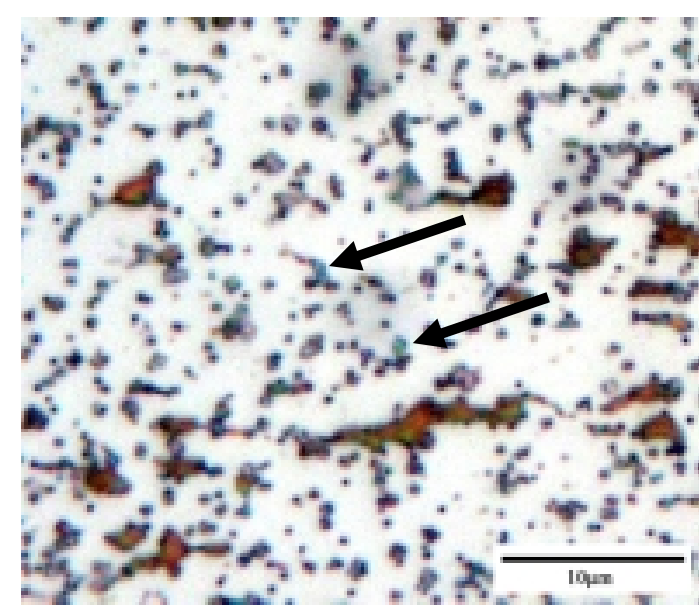

a)

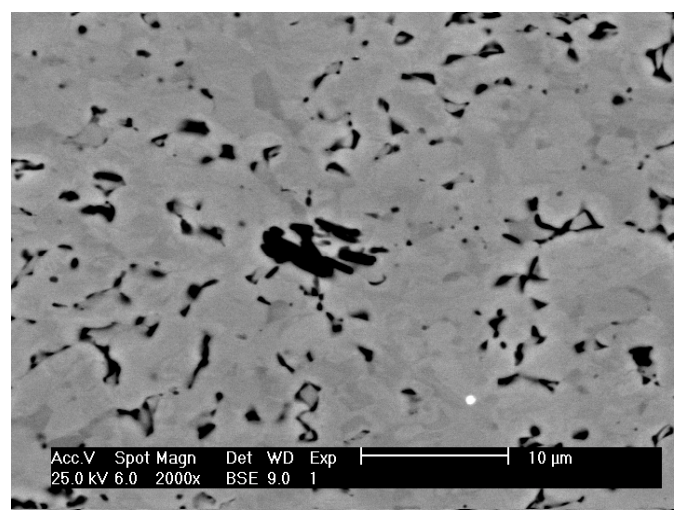

c)

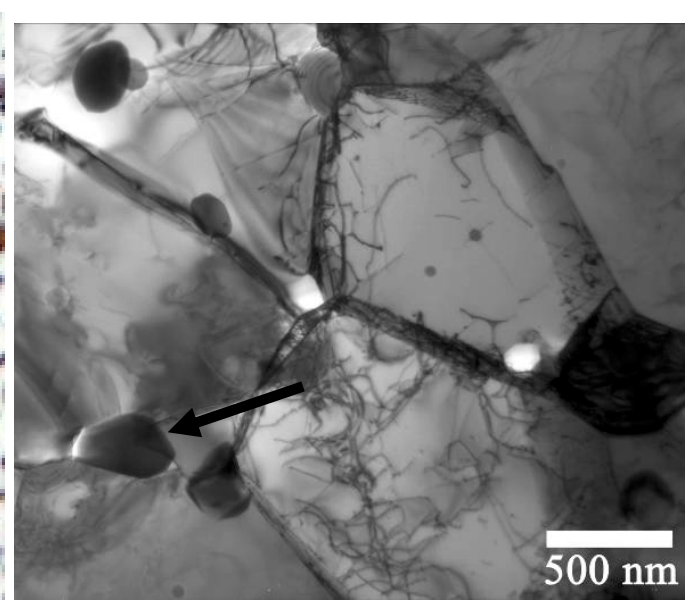

b)

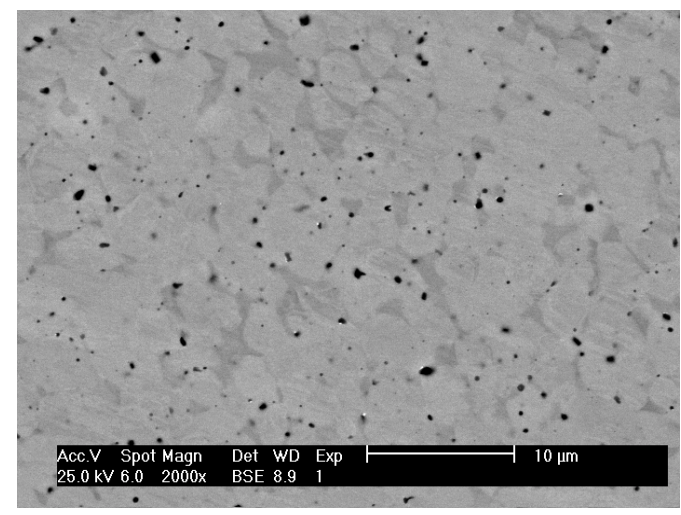

d)

Figure 15. Phase identification images a) photomicrograph showing sigma (bright blue) b) TEM negative showing sigma at a triple point and backscatter images showing austenite (light gray), ferrite (darker gray), and archives of sigma (black) located in c) the lower FS processed region and d) the upper FS processed region

Murakami's reagent further revealed that carbides were also present in the FS processed arc welds. Park et al identified $\mathrm{M}_{23} \mathrm{C}_{6}$ type carbides in FS welded 304L [Ref 40]. Like sigma, the presence of carbide can be detrimental to both corrosion and fatigue. Detailed 
optical metallography indicated that the carbides present are primarily located sub surface in the lower region of the SZ (Figure 16).

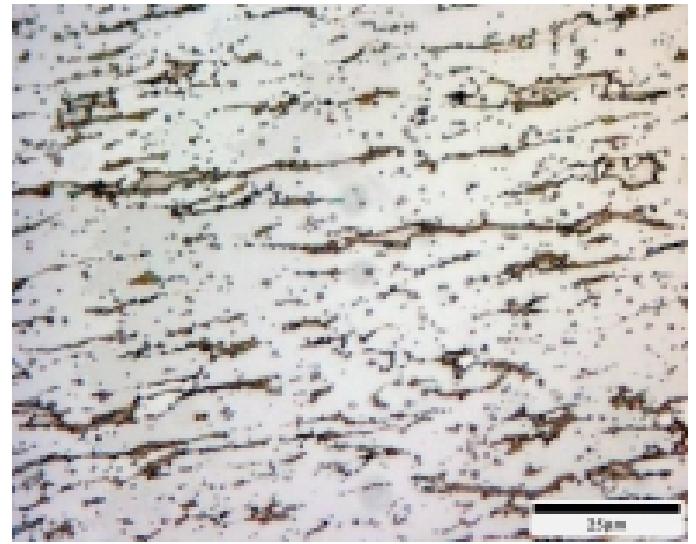

a)

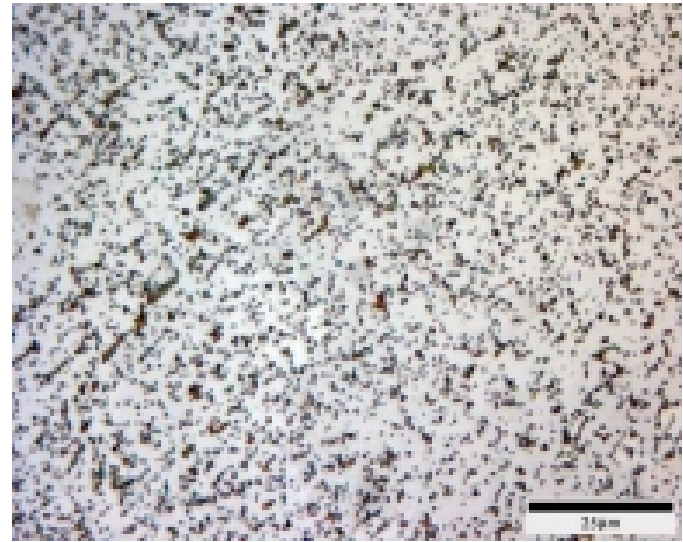

b)

Figure 16. Photomicrographs showing a) low density of carbide (small black spots) near the surface of the FS processed arc weld and b) a higher concentration of carbide at the lower region of the SZ

As discussed previously, adverse second phases, such as sigma and carbide, are always a concern. When they occur near the surface, or create a continuous path for corrosive elements to follow, they tend to accelerate corrosion and may result in premature failures. However, when second phases are discontinuous or sub-surface they are less detrimental to the materials SCC and general corrosion resistance. Due to the sub-surface location and discontinuous morphology of the sigma and carbide in FS processed 304L arc, it is believed that their presence will not adversely affect the resulting corrosion properties.

\subsection{Mechanical Properties}

\subsubsection{Microhardness}

Several observations may be made from the full microhardness map of the cross section of an FS processed arc weld shown in Figure 17. A large increase in hardness is observed near the fusion weld. This is most likely due to work hardening that occurred during plastic deformation as the plates were flattened and machined prior to FSP. The particular sample used for the microhardness map shown was only FS processed at the weld crown. The lower hardness surrounding the FS processed region indicates that the 
work hardened region was annealed by the thermal cycle inherent with FSP. This annealing reduced the hardness of the HAZ to $\sim 180 \mathrm{VHN}$. This reduction in hardness is beneficial to the fatigue life of the material due to the higher toughness that accompanies a softer material. Tough materials have a higher crack initiation resistance than hard materials and therefore a higher fatigue life.

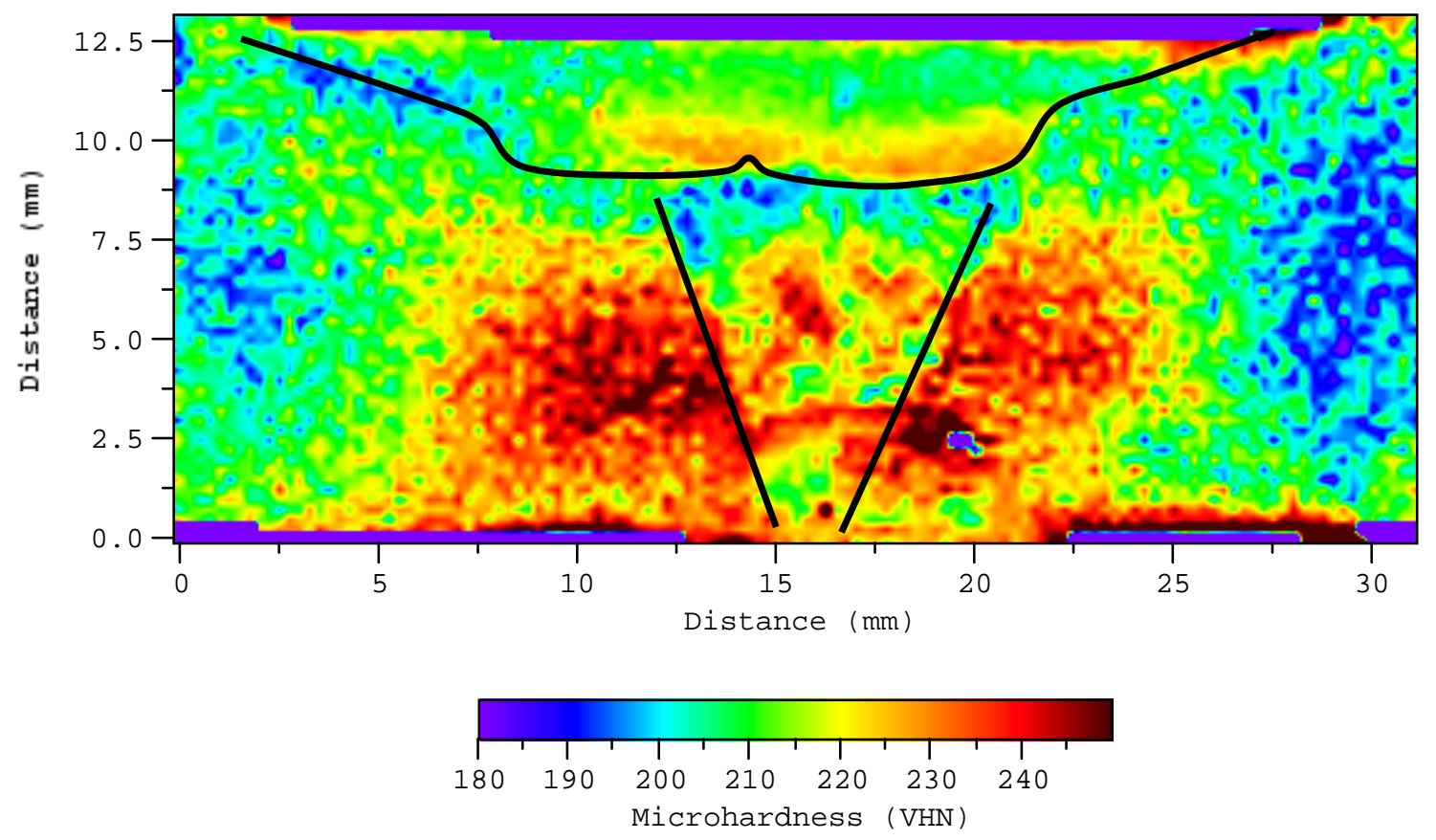

Figure 17. Microhardness Map of FS processed arc weld with lines approximating the location of the fusion weld (straight lines) and stir zone (curved line)

An area of increased hardness was observed at the lower portion of each MPR. Due to the small size and high density of the sigma and carbide particles present in this region $(\sim 100-500 \mathrm{~nm})$, it was hypothesized that this increase in hardness was due to a dispersion hardening type effect. In order to test this theory another microhardness sample was prepared. After removing the sigma and carbide present in the sample, by etching with oxalic acid, a transverse microhardness line trace was made across the bottom of both stir zones. With the sigma and carbide removed, the hardness in this region was approximately 60 points lower than the hardness of the as-polished specimen in the same region. This softening is attributed to the fact that the remaining austenite easily deforms into the voids left where the sigma and carbide phases had been preferentially etched out 
of the matrix. This result supports the hypothesis that a dispersion hardening type mechanism is responsible for the increased hardness in this region.

\subsubsection{Transverse Tensile Properties}

The results of transverse tensile tests, shown in Figure 18, indicate that FSP 304L arc welds produces an increase in tensile properties. An increase of approximately $6 \%$ was achieved for both the yield strength and tensile strength. Likewise, an increase of $36 \%$ was achieved in elongation. As it was not clear that these increases proved that FSP of arc welds produces improvements in the transverse tensile properties, statistical methods were applied to determine if the increases were significant. Comparing the standard deviations of the data with a two tailed t-test and a confidence level of $\alpha=0.05$, it was seen that there is less than a $10 \%$ chance that these increases are not actually statistically different. This indicates that while the increase may not be large, it may be said with certainty that FSP arc welds creates an increase in transverse tensile properties over the as-welded arc welds.

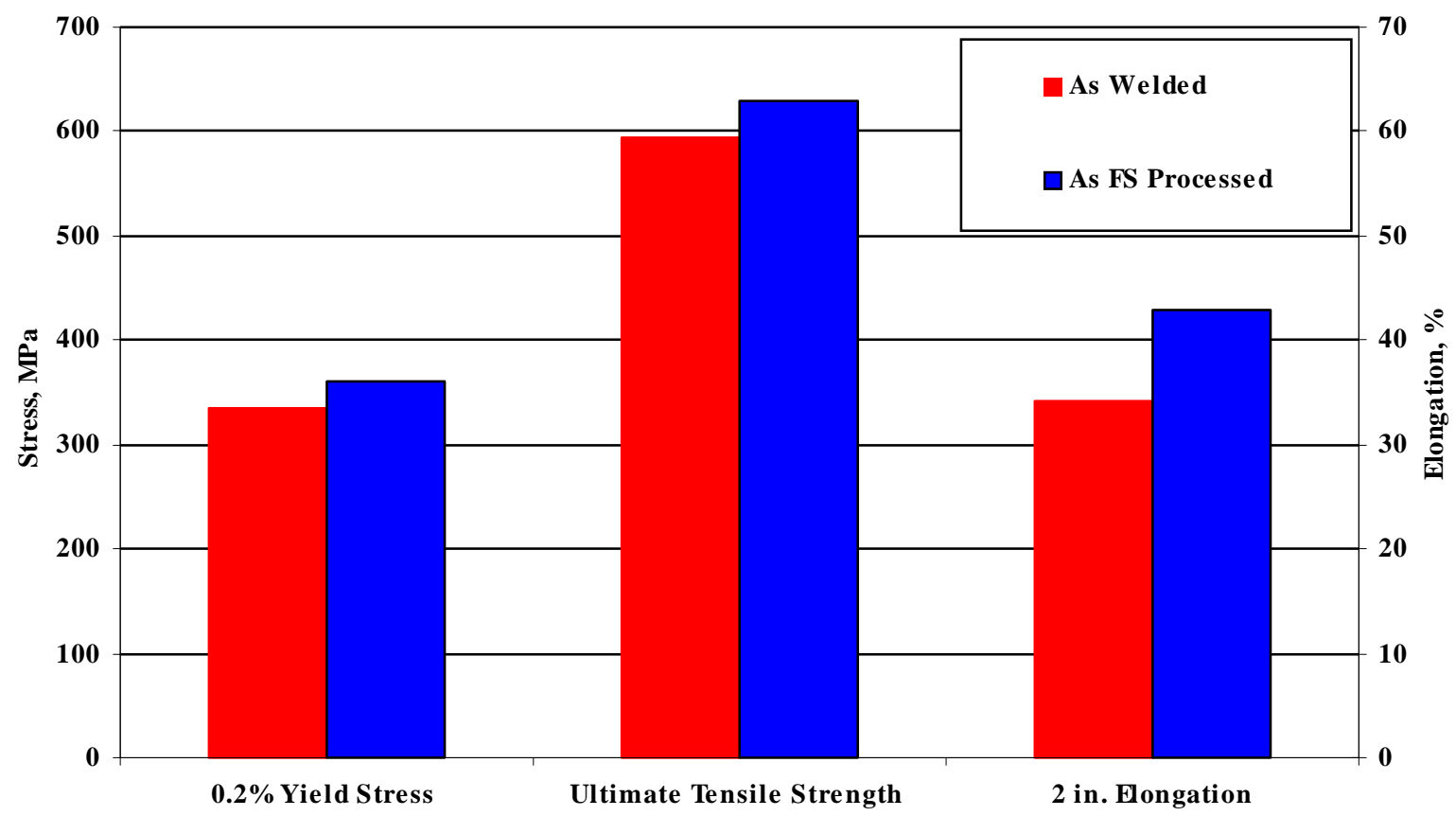

Figure 18. Comparison of tensile properties and elongation of as-welded vs. as-FS processed 


\subsubsection{Fatigue Life}

Fatigue testing in a non-corrosive environment failed to indicated that significant improvement in the fatigue life of 304L arc welds was achieved through FSP (Figure 19). The endurance limit of the as-welded arc welds was determined to be around $110 \mathrm{MPa}$, while the FS processed arc welds had an endurance limit of nearly $500 \mathrm{MPa}$. However, much of this increase in fatigue life may be linked to the lack of the stress concentration at the weld toes.

To remove the detrimental effect of the weld toes on fatigue life, and concentrate on the effects of microstructure alone, arc welds were also tested with the weld crown ground flush. Studying Figure 18 it is hard to find delineation between the SN curves for the finely ground FS processed samples vs. the finely ground arc welds.

Pertaining to fatigue life in a non-corrosive environment, it is difficult to determine if the microstructure created by FSP 304L arc welds is more favorable than the as-welded 304L microstructure. It was expected that the improved microstructure created via FSP would increase the mechanical properties of the weldments enough to have a significant effect on fatigue life. Further testing is needed to determine if a significant difference may be found in the fatigue life of the two microstructures in a non-corrosive environment. However, it is anticipated that in a corrosive environment, where 304L is most frequently used, an improvement will be attained. 


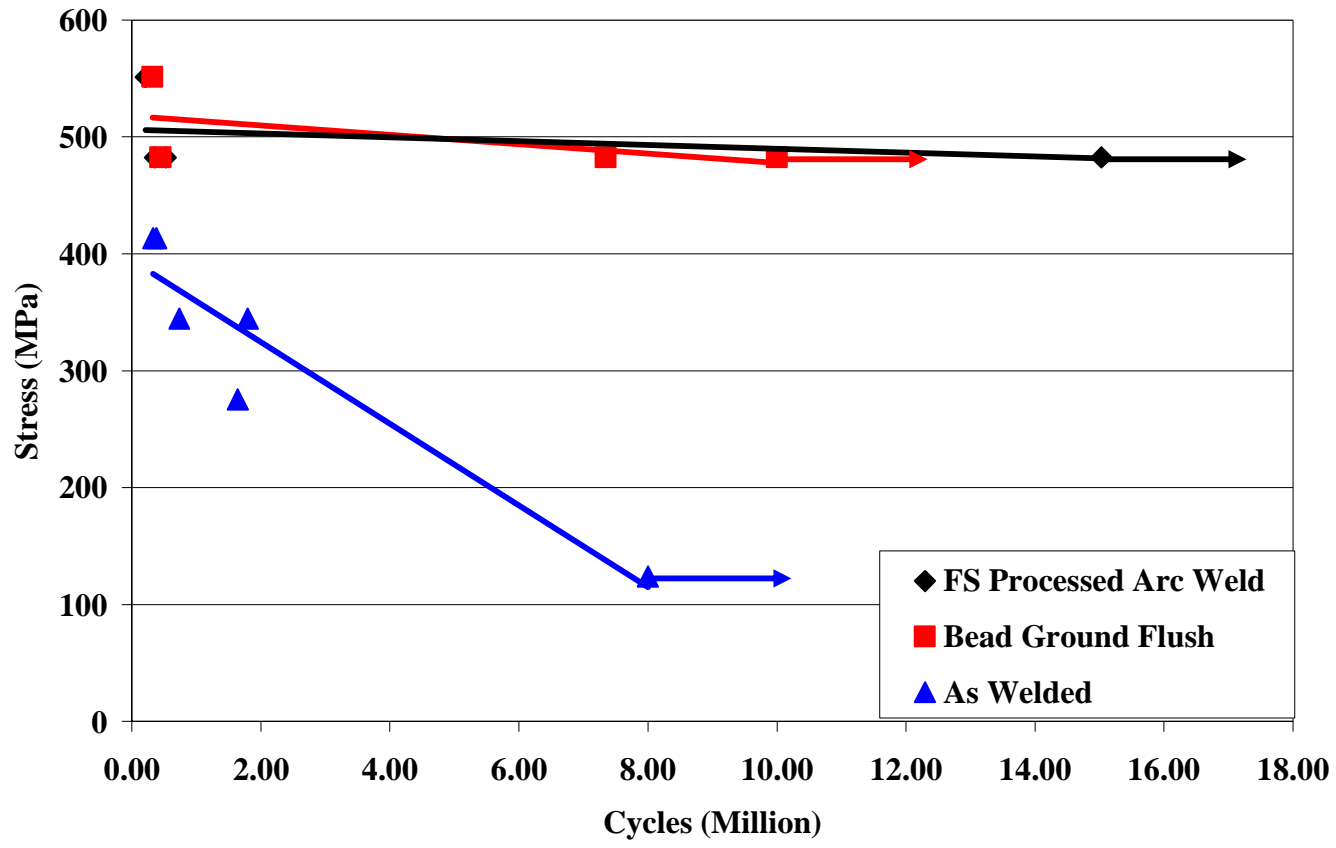

Figure 19. High cycle fatigue curve for arc welds, FS processed arc welds, and arc welds with the bead ground flush 


\section{Conclusions}

\subsection{Summary}

FSP has been successfully applied as a method to alter the microstructure and hence the mechanical properties of arc welded 304L stainless steel. Although FSP proved more difficult to implement in arc welds than the base material, a range of parameters were found that produced suitable microstructures. The resulting microstructure no longer exhibited large columnar grains, typical of a cast microstructure, nor long continuous ferrite stringers. Rather, a fine grained austenite matrix with islands of discontinuous ferrite was produced. Other improvements, such as the introduction of twins and the reorientation of ferrite that had been perpendicular to the surface of the arc weld were also achieved. The resulting microstructure is consistent with microstructures that have been proven to increase the SCC resistance of arc welds.

FSP 304L arc welds created a microstructure that is expected to increase the SCC resistance over the as-welded material by:

1. Creating a fine grain equiaxed microstructure throughout the SZ. The average ferrite grain size in the MPR was $\sim 4 \mu \mathrm{m}$, while the average austenite grain size was twice as large at $\sim 8 \mu \mathrm{m}$. The average austenite grain size in the AR was $\sim 3$ $\mu \mathrm{m}$, while the base metal's average grain size was $\sim 14 \mu \mathrm{m}$.

2. Breaking up the continuous ferrite stringers associated with arc welds.

3. Reorienting the ferrite stringers that were perpendicular to the weld surface in the as-welded condition.

4. Producing a microstructure containing 10-16\% twin boundaries throughout the SZ. 
While undesirable, the presence of sigma and carbide is not expected to be detrimental to the SCC resistance or general corrosion resistance of FS processed arc welds due to their sub-surface location and discontinuous morphology.

Improvements in transverse tensile properties have also been attributed to these microstructural improvements. FSP increased the ultimate and yield strength of $304 \mathrm{~L}$ arc welds by $6 \%$. Likewise an increase of $36 \%$ was achieved in elongation.

\subsection{Contributions}

This work has provided quantitative results, as well as contributions to the general process that will improve FS research. The process used, and knowledge gained during this study, will enable researchers to expedite their investigations in the future. The quantitative results have been discussed in the previous section and the process contributions will be discussed here.

As this is the first reported instance that FSP has been applied to welds in stainless steel the following contributions have been made:

1. A range of FSP parameters have been identified that produce fully consolidated, metallurgically sound microstructures in 304L. These parameters will save future researchers time and money.

2. It has been shown that FSP arc welds with the advancing side of the tool towards the center of the existing arc weld reduces the exposed area of dual-phase material.

3. It is now known that the dual-phase nature of $304 \mathrm{~L}$ arc welds makes FSP more challenging than $304 \mathrm{~L}$ base material.

4. Names, and acronyms, have been given to two previously un-named regions; MPR, and AR. The naming of these regions will simplify discussions and research for other FS researchers. 


\subsection{Future Work}

While significant work has been accomplished in this study, there are some important areas that would be beneficial to investigate in the future and are listed below:

1. A microstructure has been produced that is expected to increase SCC resistance. However, SCC tests need to be performed so that the improvement may be quantified.

2. Although SCC is related to the yield strength of a material, it is also greatly affected by residual stresses. Therefore, residual stress measurements should be performed to compare the stress state of the arc welds and the FS processed arc welds.

3. As the endurance limit of arc welds in a corrosive environment depends on the microstructure, extensive fatigue testing would indicate whether the FS processed microstructure is an improvement over the as-welded arc welds.

4. Since sigma is known to reduce the fracture toughness of materials, testing should be completed to determine the effect of sub-surface sigma and carbide present in FS processed 304L arc welds on this important mechanical property.

These tests coupled with the work completed in this study, would complete a comprehensive study on the microstructural and mechanical effects of FS processed 304L arc welds. 


\section{References}

1. A.Z. Sadek, A.M. El-Sheikh, "Failure Analysis of SS 304 Weldments by Metallurgically Enhanced Stress Corrosion Cracking in Laboratory Environments," Corrosion 2000, Orlando, FL, March 2000.

2. M. Palaniappan et al, "Effect of Repeated Repairs on the Stainless Steel Welds upon the Ultrasonic Examination Sensitivity," $14^{\text {th }}$ World Conference on Non Destructive Testing, New Delhi, India, December 1996.

3. K.G. Reddy et al, "Analysis of Corroded Austenitic Stainless Steel Welds," Praktishe Metallographie (Practical Metallurgy), vol. 37, no. 11, pp 600-607, November 2000.

4. K.V. Vannan, B. Thangavel, "Occurrence of Delta Ferrite in Type 304/304L Stainless Steel Pipe Welds," The Third International Symposium of the Japan Welding Society, Tokyo, Japan, September 1978.

5. R.K. Malik, "HIP Heals Defects in Austenitic Stainless Steel Welds," Metal Progress," vol. 119, no. 4, pp. 86-90, March 1981.

6. S.A. David et al, "Solidification Behavior of Austenitic Stainless Steel Filler Metals," Welding Journal, vol. 58, no. 11, pp. 330s-336s, November 1979.

7. N. Suutala et al, "Ferritic-Austenitic Solidification Mode in Austenitic Stainless Steel Welds," Metallurgical Transactions A," vol. 11A, pp 717-725, May 1980.

8. H. Inoue et al, "Effect of Solidification and Subsequent Transformation on Ferrite Morphologies in Austenitic Stainless Steel Welds," 6th JWS International Symposium, Nagoya, Japan, November 1996.

9. N. Rothwell, M.E.D. Turner, "Corrosion Problems Associated with Weldments," Met. Mater., vol. 5, no. 6, pp. 352-354, June 1989. 
10. A. Garner, "Corrosion Mechanisms in Austenitic Stainless Steel Welds," Fourth International Symposium on Corrosion in the Pulp and Paper Industry, Stockholm, Sweden, June 1983.

11. K.N. Krishnan, K. Prasad Rao, "Effect of Microstructure on Stress Corrosion Cracking Behaviour of Austenitic Stainless Steel Weld Metals," Materials Science and Engineering, A142, pp. 79-85, 1991.

12. E.A. Loria, Discussion of "Stress Corrosion Cracking of Welded Type 304 and 304L Stainless Steel Under Cyclic Loading," Corrosion, vol. 37, no.4, pp.243-246 April 1981.

13. TWI; W.M. Thomas, E.D. Nicholas, J.C. Needham, P. Temple-Smith, S. Kallee, WKW; C.J. Dawes, UK Patent Application 2306366 A, Filed: 17 Oct.1996 (UK 9521570, 20 Oct.1995; 9523827, 22 Nov.1995; 9605864, 20 Mar.1996)

14. The Welding Institute; W.M. Thomas, E.D. Nicholas, J.C. Needham, M.G. Murch, P. Temple-Smith, and C.J. Dawes, PCT World Patent Application WO 93/10935.

15. M.A. Sutton, A.P. Reynolds, D.Q. Wang, C.R. Hubbard, Material Technology, $2002 ; 124 ; 215$.

16. M James, M Mahoney, D Waldron, $1^{\text {st } I n t e r n a t i o n a l ~ S y m p o s i u m ~ o n ~ F r i c t i o n ~ S t i r ~}$ Welding, Thousand Oaks, CA, June 1999.

17. J.C. Lippold, P.J. Ditzel, "Friction Stir Welding of Aluminum Alloys," THERMEC 2003, Leganés, Madrid, Spain, July 2003.

18. C-G Andesson, R.E. Andrews, "Fabrication of Containment Canisters for Nuclear Waste by Friction Stir Welding," ${ }^{\text {st }}$ International Symposium on Friction Stir Welding, Thousand Oaks, CA, June 1999.

19. I.D. Harris, "Reduction of Worker Exposure and Environmental Release of Welding Emissions, Task 1-Current Shipyard Practice," EWI Project No. 43149GTH, November 2000.

20. T.J. Lienert et al, "Friction Stir Welding of DH-36 Steel," AWS, 2003.

21. W.M. Thomas et al, "Feasibility of Friction Stir Welding Steel," Science and Technology of Welding and Joining, vol. 4, no. 6, pp. 365-372, 1999. 
22. T.J Lienert, J.E. Gould, "Friction Sir Welding of Mild Steel," $\underline{1}^{\text {st }}$ IFSW, Thousand Oaks, CA, 1999.

23. T.J. Lienert et at, "Friction Stir Welding Studies on Mild Steel," Welding Journal, vol. 82, no. 1, pp. 1s-9s, 2003.

24. R.J. Steel et al, "Friction Stir Welding of SAF 2507 (UNS S32750) Super Duplex Stainless Steel," Stainless Steel World 2003, Maastricht, Netherlands, Nobember 2003.

25. C.D. Sorensen, T.W. Nelson and S. Packer, "Tool Material Testing for FSW of High-Temperature Alloys," 3rd International Symposium of Friction Stir Welding, Kobe, Japan, Sept. 2001.

26. C.J. Sterling et al, "Friction Sir Welding of Quenched and Tempered C-Mn Steel," Friction Stir Welding and Processing II, TMS, 2003.

27. C.J. Sterling et al, "Effects of Friction Stir Processing on the Microstructure and Mechanical Properties of Fusion Welded 304L Stainless Steel,” THERMEC 2003, Leganés, Madrid, Spain, July 2003.

28. T.W. Nelson et al, "Friction Stir Welding of High Temperature Materials", Proceedings of the $6^{\text {th }}$ International Conference on Trends in Welding Research", Pine Mountain, GA, April 2002.

29. Okamoto et al, "Metallurgical and Mechanical Properties of Friction Stir Welded Stainless Steels," $4^{\text {th }}$ International Symposium on Friction Stir Welding, Park City, UT, May 2003.

30. S. Packer et al, "Tool and Equipment Requirements for Friction Stir Welding Ferrous and Other High Melting Temperature Alloys," $4^{\text {th }}$ International Symposium on Friction Stir Welding, Park City, UT, May 2003.

31. M.W. Mahoney et al, "High Strain Rate, Thick Section Superplasticity Created via Friction Stir Processing," Friction Stir Welding and Processing, TMS, 2001.

32. M.P. Miles et al, "Finite Element Simulation of Plane-Strain Thick Plate Bending of Friction-Stir Processed 2519 Aluminum," Friction Stir Welding and Processing II, TMS, 2003.

33. J-Q Su et al, “A New Route to Bulk Nanocrystalline Materials,” Journal of Material Research, vol. 18, no. 8, pp. 1757-1760, August 2003. 
34. J-Q Su et al, "Fabrication of Bulk Nanostructured Materials by Friction Stir Processing," MS\&T 2003, Chicago, IL, October 2003.

35. M.W. Mahoney et al, "Microstructural Modification and Resultant Properties of Friction Stir Processed Cast NiAl Bronze,” THERMEC 2003, Leganés, Madrid, Spain, July 2003.

36. Z.Y. Ma et al, "Microstructural Modification of Cast Aluminum Alloys via Friction Stir Processing,” THERMEC 2003, Leganés, Madrid, Spain, July 2003.

37. C. Fuller et al, "Friction Stir Processing of Aluminum Fusion Welds," $4^{\text {th }}$ International Symposium on Friction Stir Welding, Park City, UT, May 2003.

38. E.O. Hall, Proc. Phys. Soc., London 1951.

39. N.J. Petch J. Iron Steel Inst, 1953.

40. Park et al, "Rapid Formation of the Sigma Phase in 304 Stainless Steel During Friction Stir Welding," Scripta Materialia, vol. 49, no. 12, pp. 1175-1180, December 2003.

41. J. Barcik, "Mechanism of $\sigma$-Phase Formation in Cr-Ni Austenitic Steels," Materials Science and Technology, vol. 4, no. 1, pp. 5-15, January 1988.

42. G.F. Vander Voort, Metallography Principles and Practice, ASM International, 1999.

43. R.J. Steel, C.J. Sterling "Friction Stir Welding of 2205 Duplex Stainless and 3Cr12 Steels,” ISOPE ’04, Toulon, France, May 2004. 